\title{
Novel Pt(IV) Pro-drugs Displaying Antimitochondrial Effects
}

Leila Tabrizi ${ }^{1, \dagger}$ Kerry Thompson, ${ }^{2, \dagger}$ Katarzyna Mnich, ${ }^{3}$ Chetan Chintha, ${ }^{3}$ Adrienne M. Gorman, ${ }^{3}$ Liam Morrison, ${ }^{4}$ Janna Luessing, ${ }^{5}$ Noel F. Lowndes, ${ }^{5}$ Peter Dockery, ${ }^{2}$ Afshin Samali,${ }^{3 *}$ Andrea Erxleben $^{1, *}$

\footnotetext{
${ }^{1}$ School of Chemistry, National University of Ireland, Galway, Ireland

${ }^{2}$ Anatomy, School of Medicine, National University of Ireland, Galway, Ireland

${ }^{3}$ Apoptosis Research Centre, School of Natural Sciences, National University of Ireland, Galway, Ireland

${ }^{4}$ Earth and Ocean Sciences, School of Natural Sciences and Ryan Institute, National University of Ireland, Galway, Ireland

${ }^{5}$ Genome Stability Laboratory, Centre for Chromosome Biology, School of Natural Sciences, National University of Ireland, Galway, Ireland

*Corresponding author email address: andrea.erxleben@nuigalway.ie (AE); afshin.samali@nuigalway.ie (AS)

$\dagger$ Joint first authors
}

\section{Supporting Information}




\section{Synthesis of 4-phenylquinazoline-2-carboxylic acid, L1}

A solution of glyoxylic acid $(10.0 \mathrm{mmol}, 0.741 \mathrm{~g})$ in water $(10 \mathrm{~mL})$ was added dropwise to a solution of 2-aminobenzophenone $(10.0 \mathrm{mmol}, 1.972 \mathrm{~g})$ and ammonium acetate $(30.0 \mathrm{mmol}$, $2.312 \mathrm{~g})$ in absolute ethanol $(30 \mathrm{~mL})$. The mixture was stirred at room temperature for $10 \mathrm{~min}$. After addition of $20 \mathrm{~mL}$ of water, the orange solid was collected by filtration and washed with absolute ethanol and diethyl ether to give 1,2-dihydro-4-phenylquinazoline-2-carboxylic acid which was dissolved in DMF $(15 \mathrm{~mL})$ and allowed to stand for $18 \mathrm{~h}$ under external light irradiation with a $20 \mathrm{~W}$ halogen tungsten lamp. After addition of $15 \mathrm{~mL}$ of water, the mixture was cooled in an ice bath for $24 \mathrm{~h}$ and the yellow precipitate formed was collected by filtration and washed with water $(3 \mathrm{~mL})$ and diethyl ether $(5 \mathrm{~mL})$ to give 4-phenylquinazoline-2carboxylic acid which was recrystallized from acetonitrile/ $\mathrm{H}_{2} \mathrm{O}(8: 3)$ (yield: $\left.1.825 \mathrm{~g}, 73 \%\right) .{ }^{1} \mathrm{H}$ NMR $\left(\mathrm{CDCl}_{3}\right): \delta 8.33\left(\mathrm{t}, 1 \mathrm{H}, \mathrm{H}-\mathrm{Ar},{ }^{3} J=10 \mathrm{~Hz}\right), 8.25\left(\mathrm{t}, 1 \mathrm{H}, \mathrm{H}-\mathrm{Ar},{ }^{3} J=10 \mathrm{~Hz}\right), 8.03-8.08(\mathrm{~m}$, 1H, H-Ar), 7.75-7.82 (m, 3H, H-Ar), 7.58-7.63 (m, 3H, H-Ar). ${ }^{13} \mathrm{C}$ NMR $\left(\mathrm{CDCl}_{3}\right): \delta 169.7$, $162.8,151.1,150.2,135.2,130.3,130.2,129.8,128.8,127.5,123.3$. ESI-MS: $251.0821[\mathrm{M}+$ $\mathrm{H}]^{+}$. 


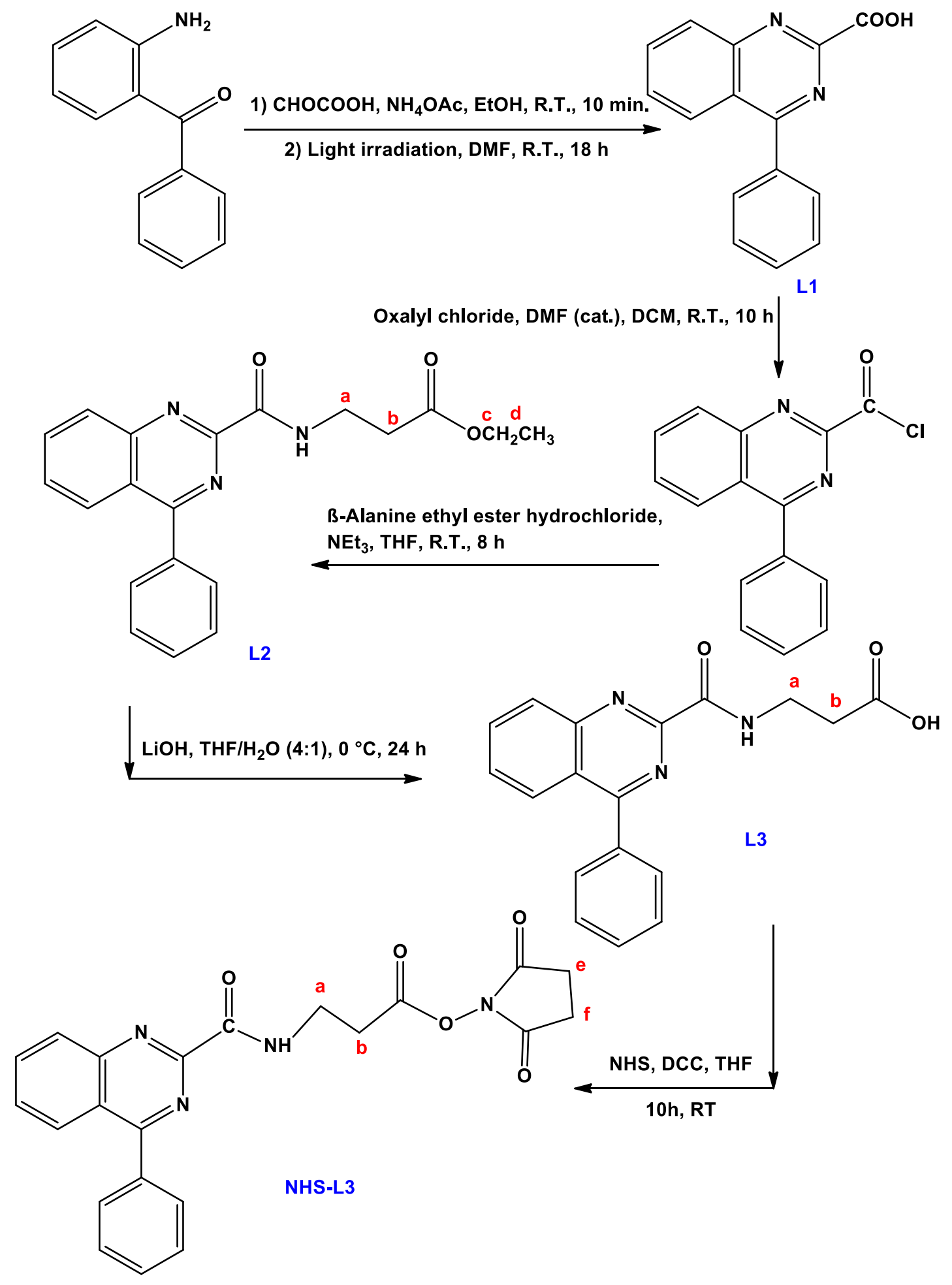

Scheme S1. Synthetic pathway of L1, L2, L3, and NHS-L3. 


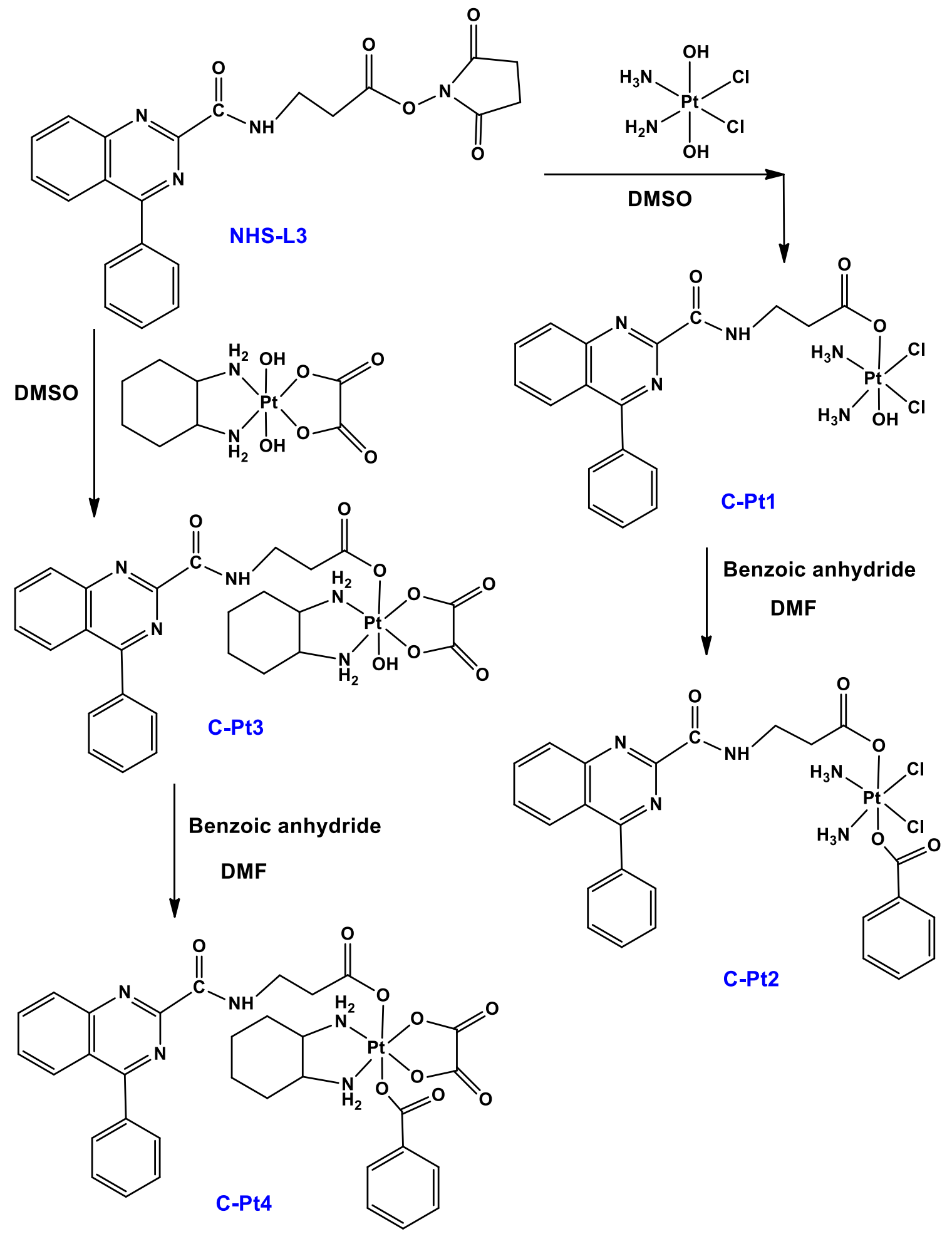

Scheme S2. Synthetic pathway of complexes C-Pt1, C-Pt2, C-Pt3, and C-Pt4. 


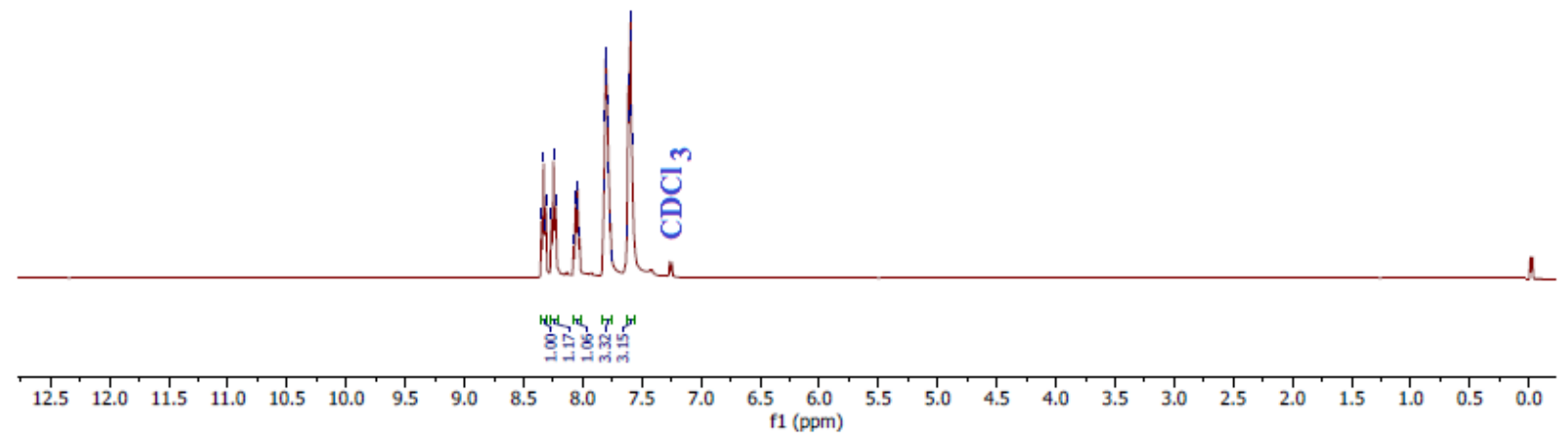

Figure S1. ${ }^{1} \mathrm{H}$ NMR spectrum of $\mathbf{L 1}\left(\mathrm{CDCl}_{3}\right)$.
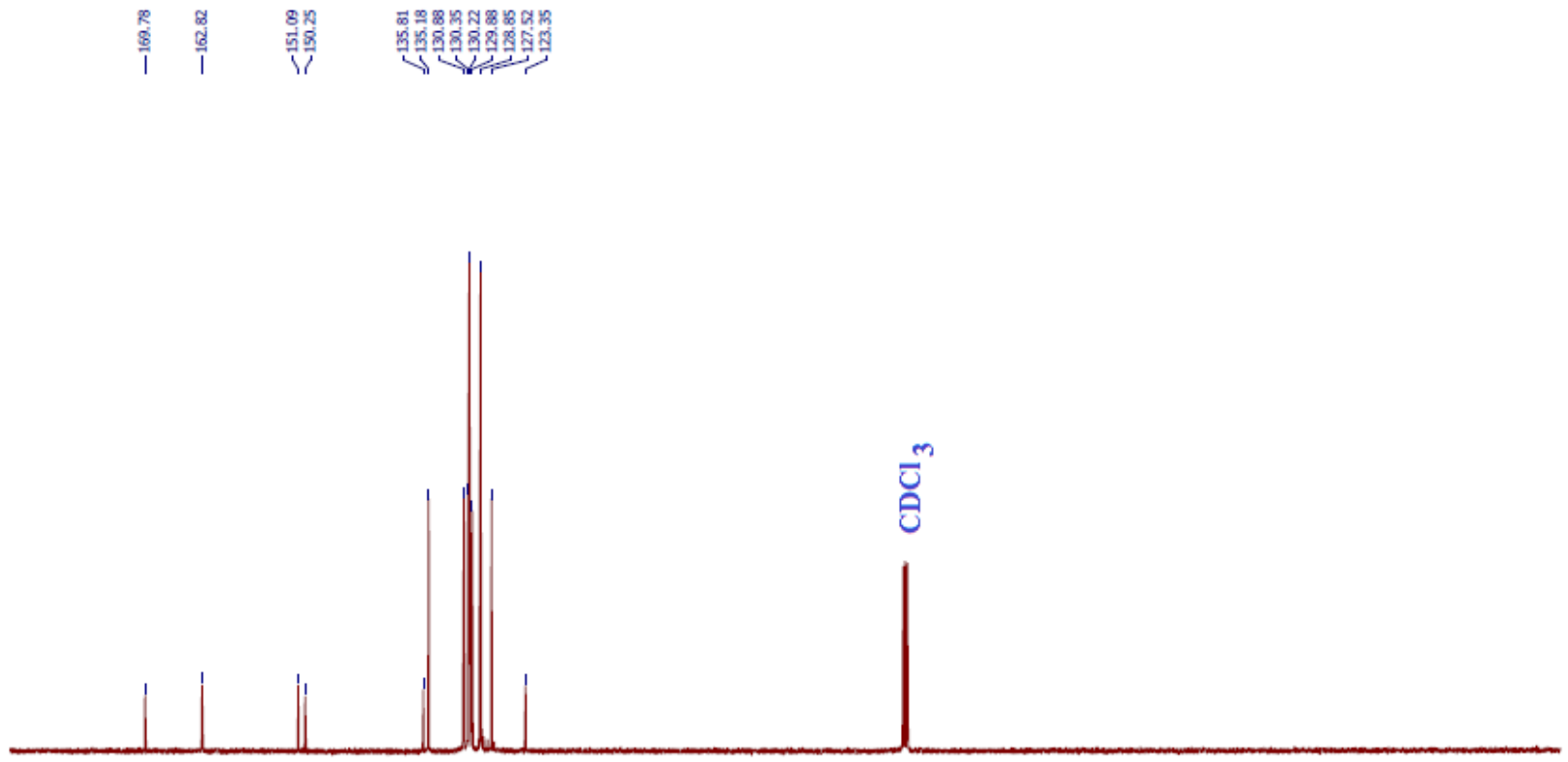

Figure S2. ${ }^{13} \mathrm{C}$ NMR spectrum of $\mathbf{L 1}\left(\mathrm{CDCl}_{3}\right)$. 

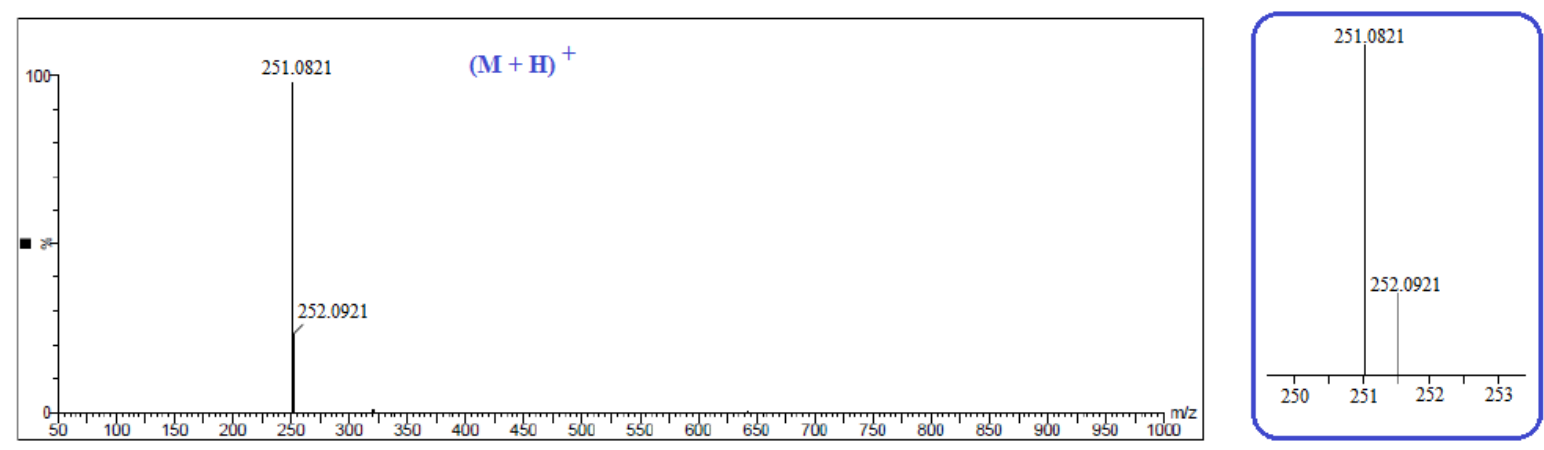

Figure S3. ESI-MS spectrum of L1.
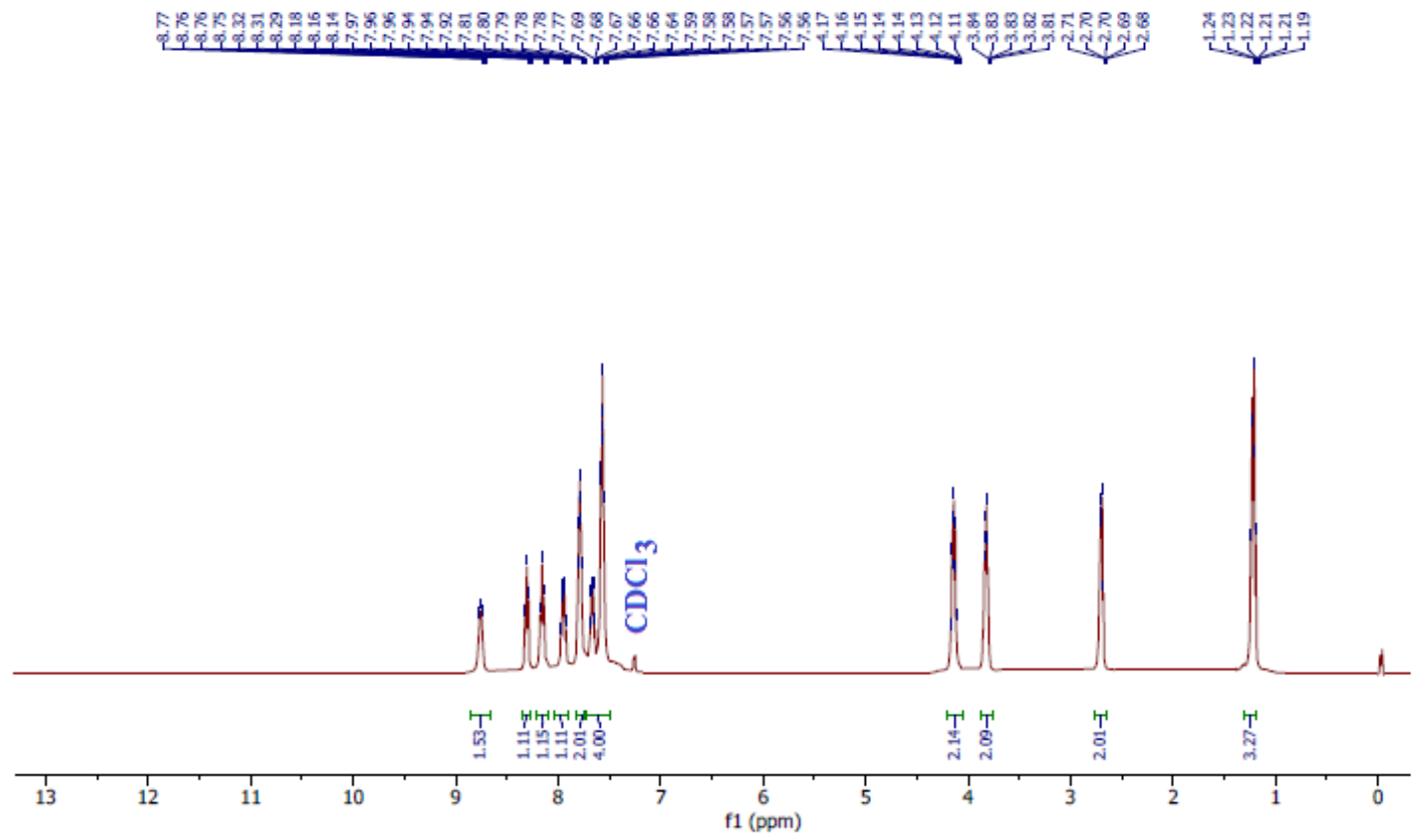

Figure S4. ${ }^{1} \mathrm{H}$ NMR spectrum of $\mathbf{L 2}\left(\mathrm{CDCl}_{3}\right)$. 


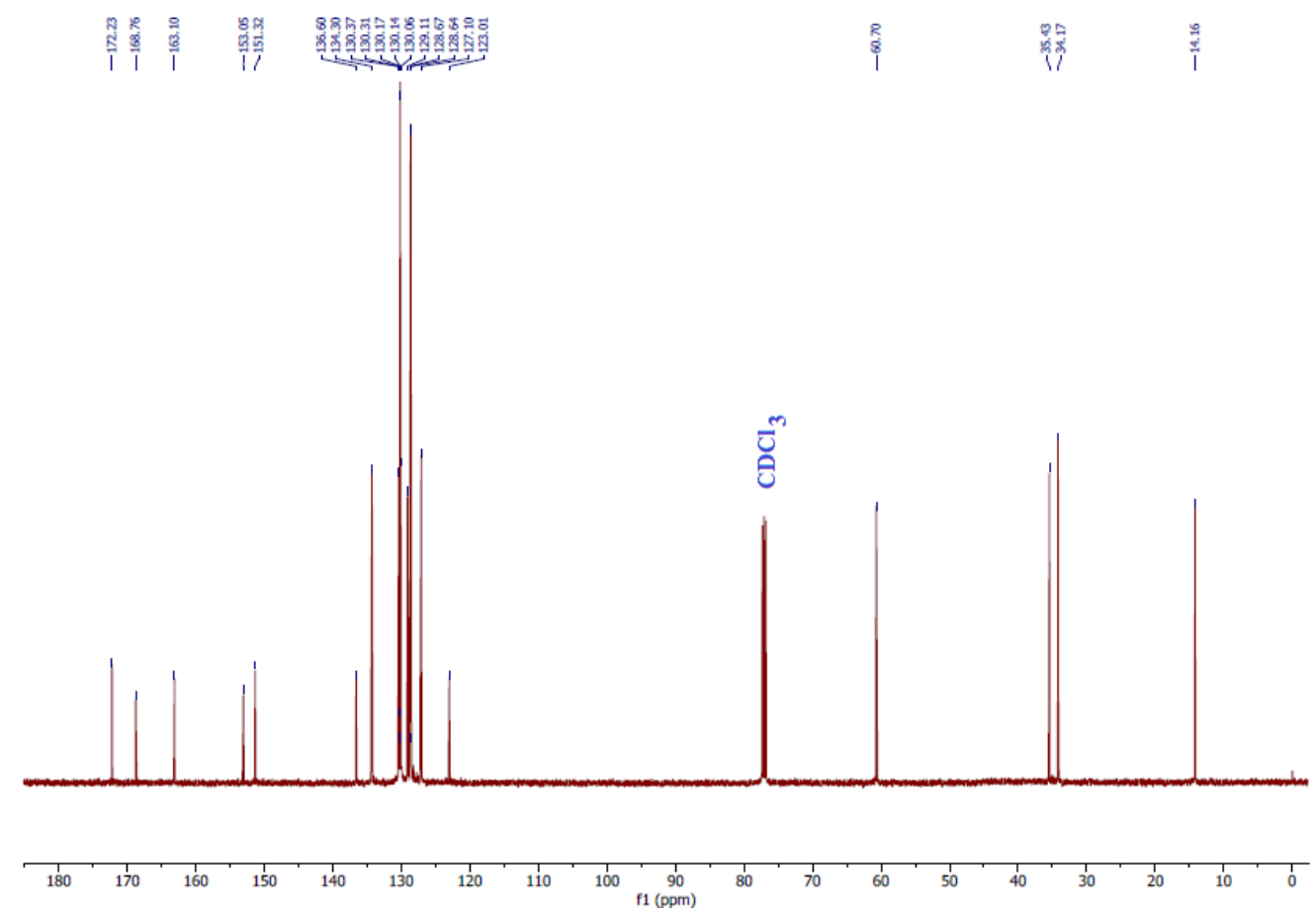

Figure S5. ${ }^{13} \mathrm{C}$ NMR spectrum of $\mathbf{L 2}\left(\mathrm{CDCl}_{3}\right)$.
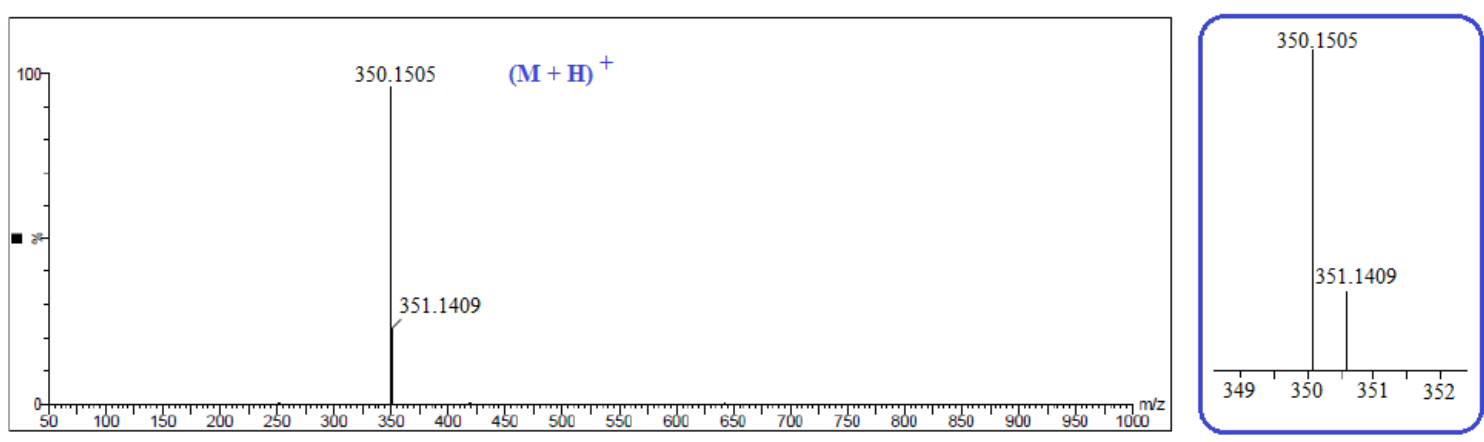

Figure S6. ESI-MS spectrum of $\mathbf{L 2}$. 


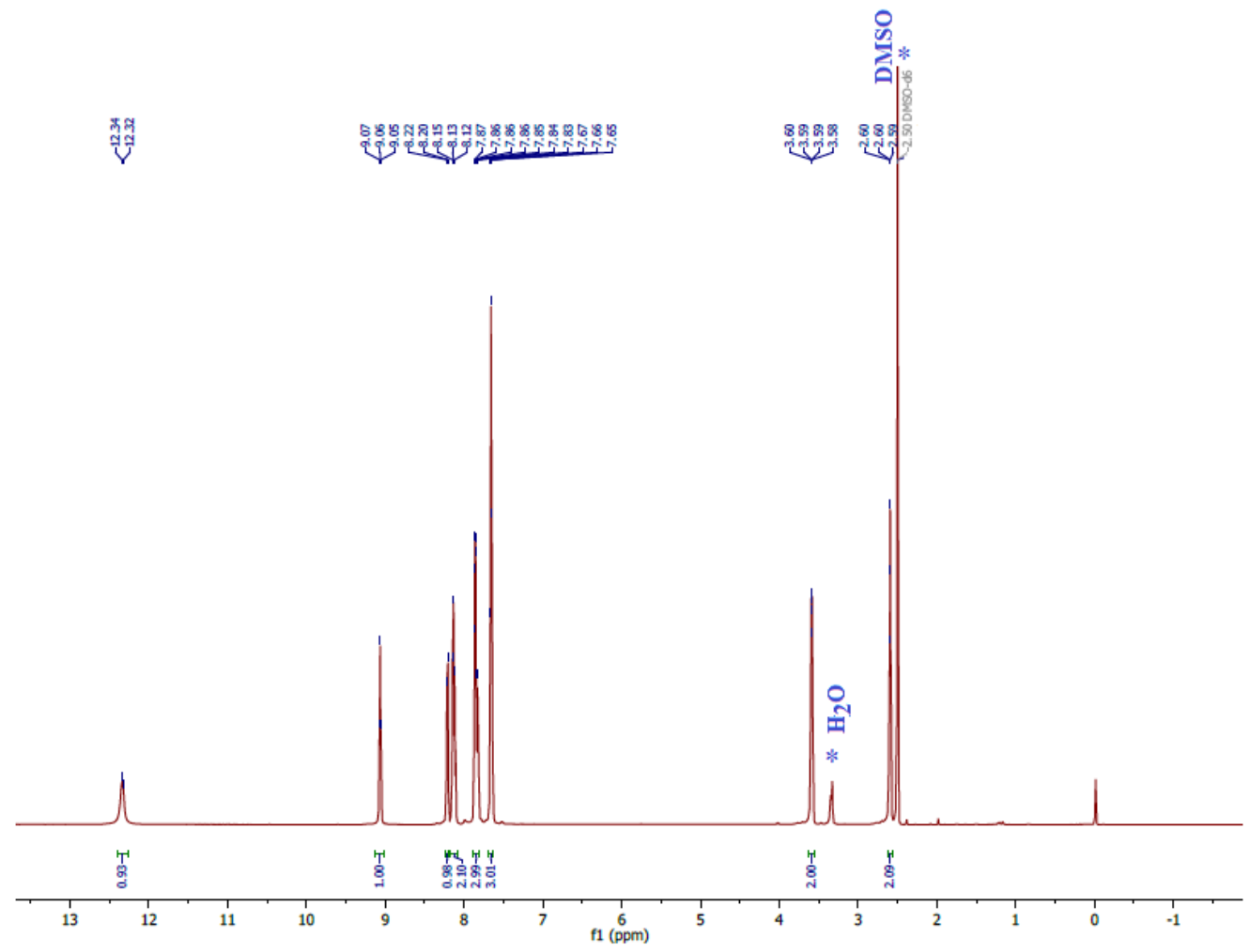

Figure S7. ${ }^{1} \mathrm{H}$ NMR spectrum of L3 (DMSO- $d_{6}$ ).

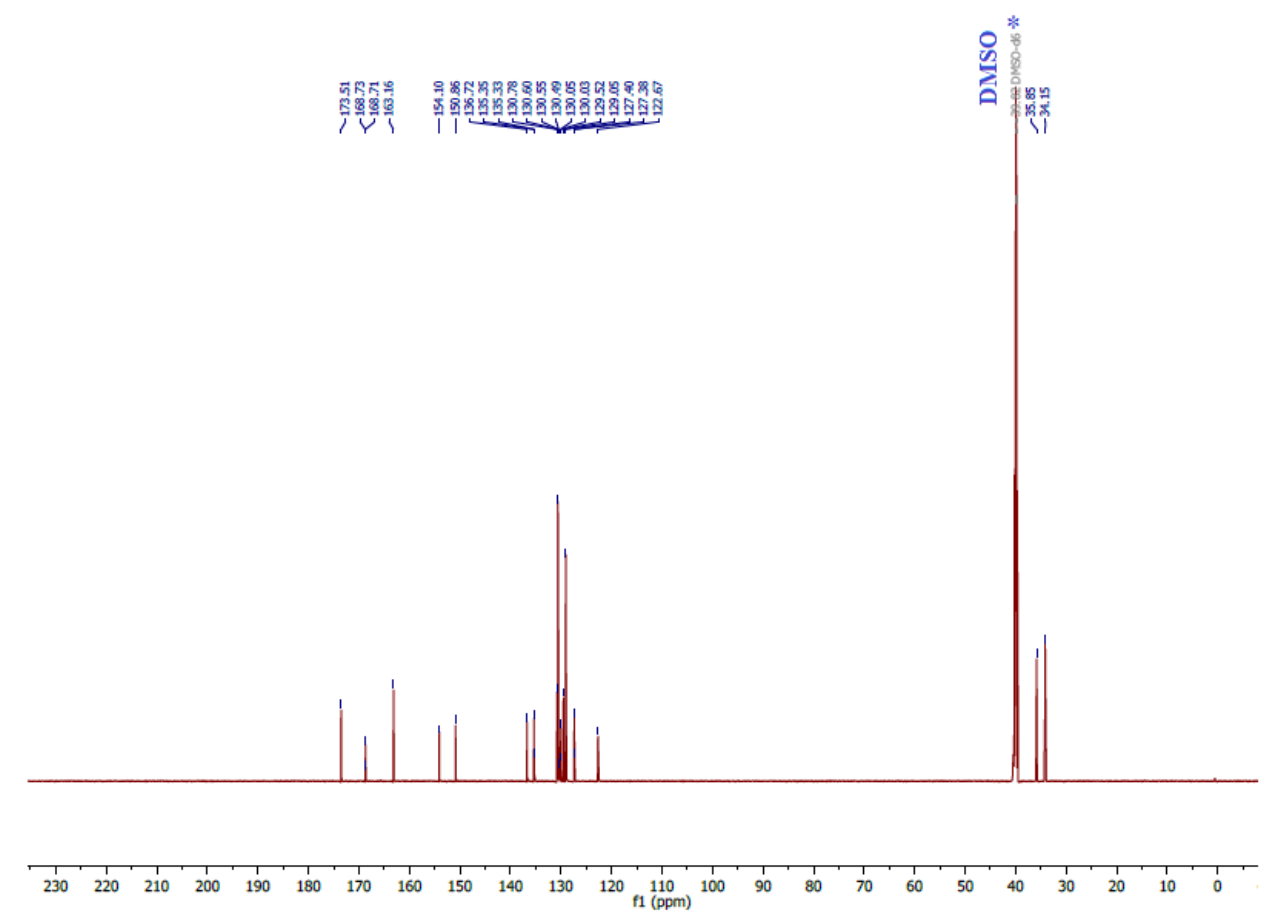

Figure S8. ${ }^{13} \mathrm{C}$ NMR spectrum of $\mathbf{L 3}$ (DMSO- $\left.d_{6}\right)$. 


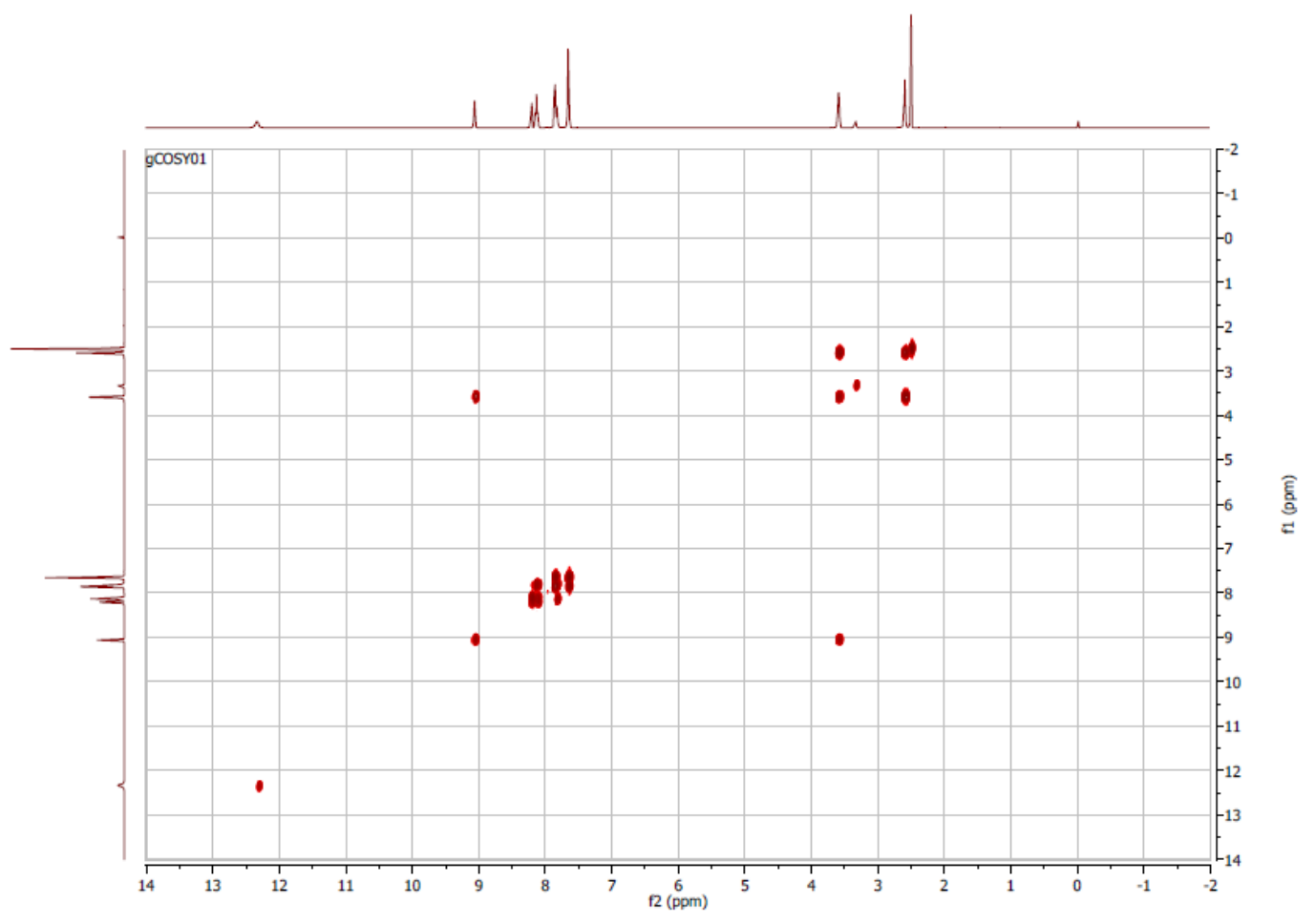

Figure S9. COSY NMR spectrum of L3 (DMSO- $\left.d_{6}\right)$.

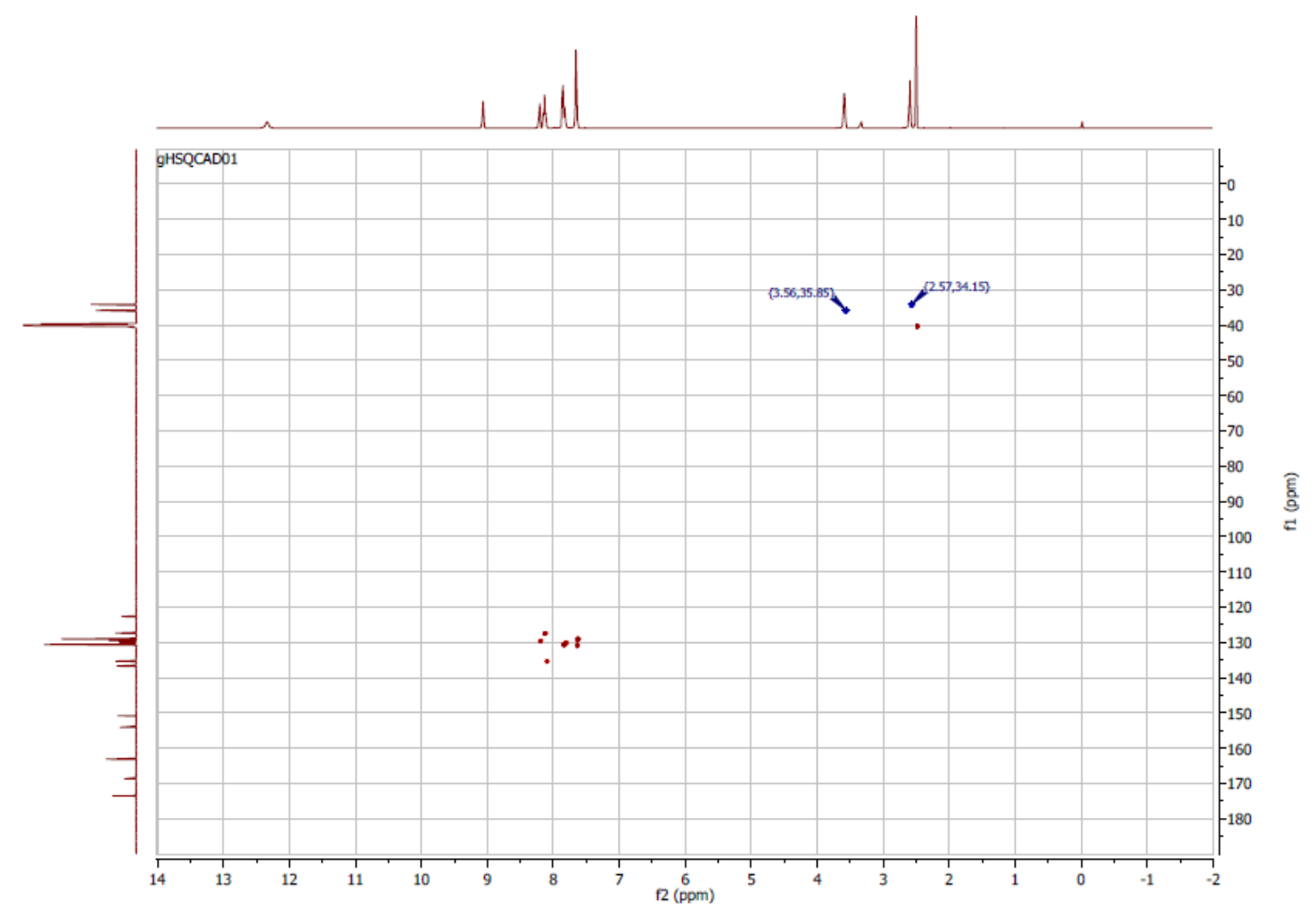

Figure S10. HSQC NMR spectrum of L3 (DMSO- $d_{6}$ ). 


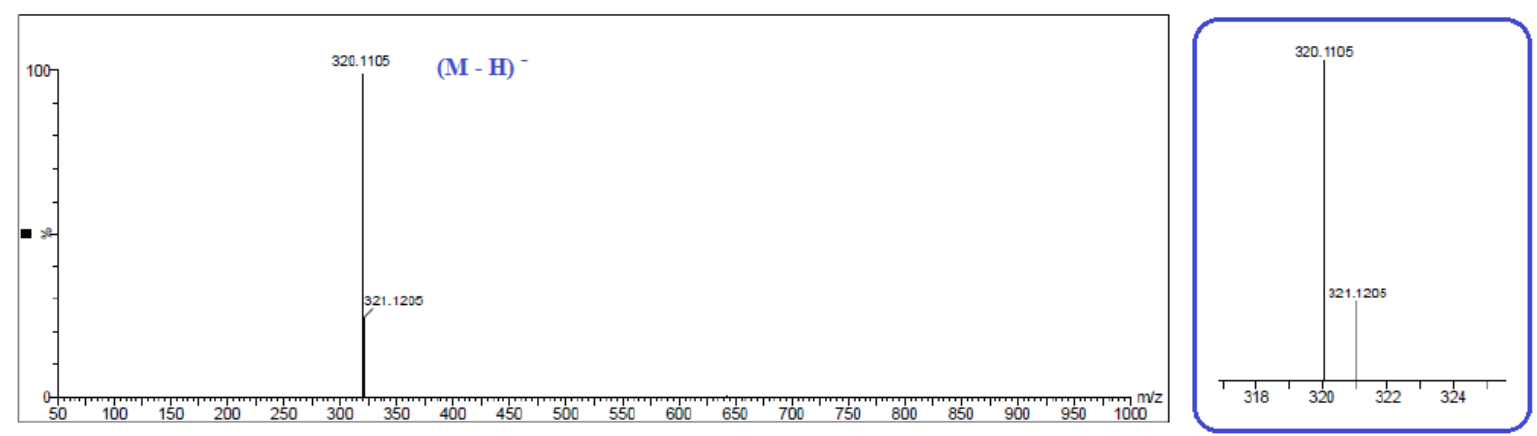

Figure S11. ESI-MS spectrum of L3.

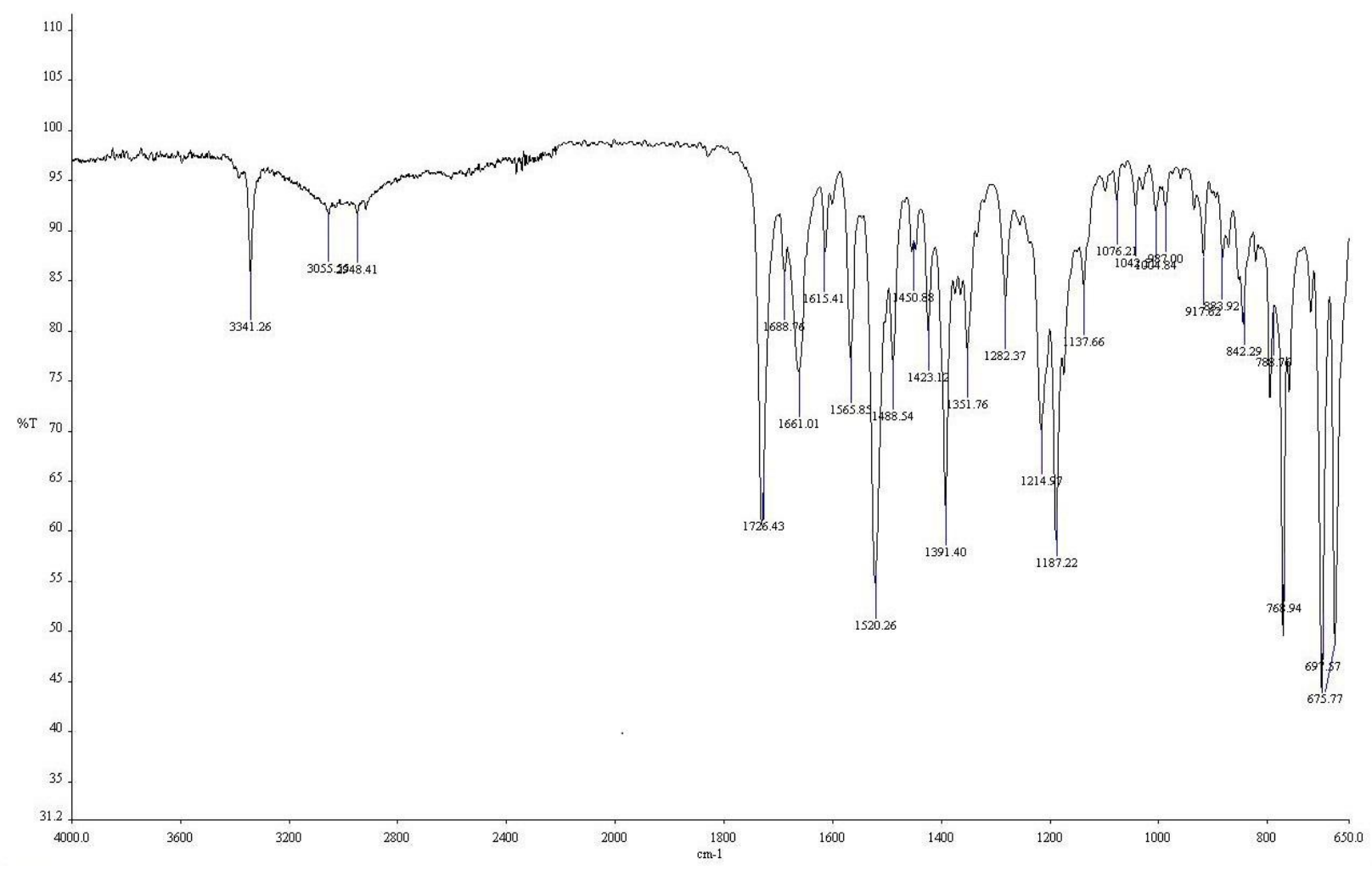

Figure S12. IR spectrum of L3. 


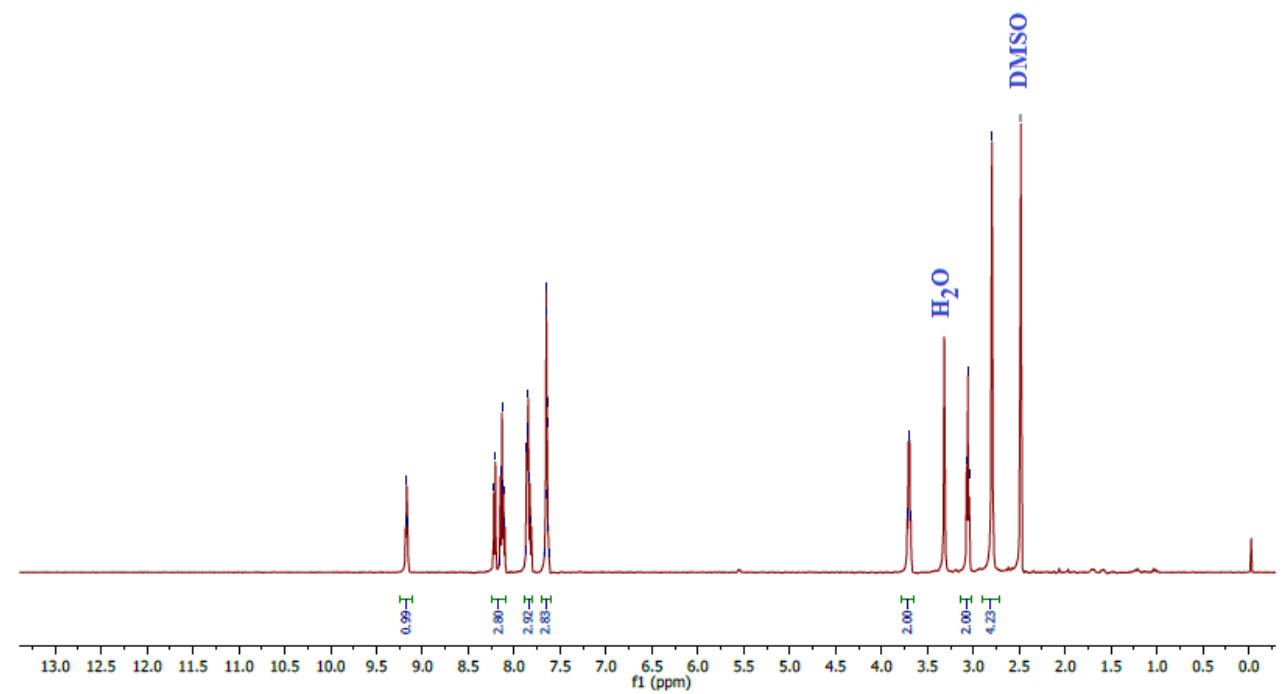

Figure S13. ${ }^{1} \mathrm{H}$ NMR spectrum of NHS-L3 (DMSO- $\left.d_{6}\right)$.

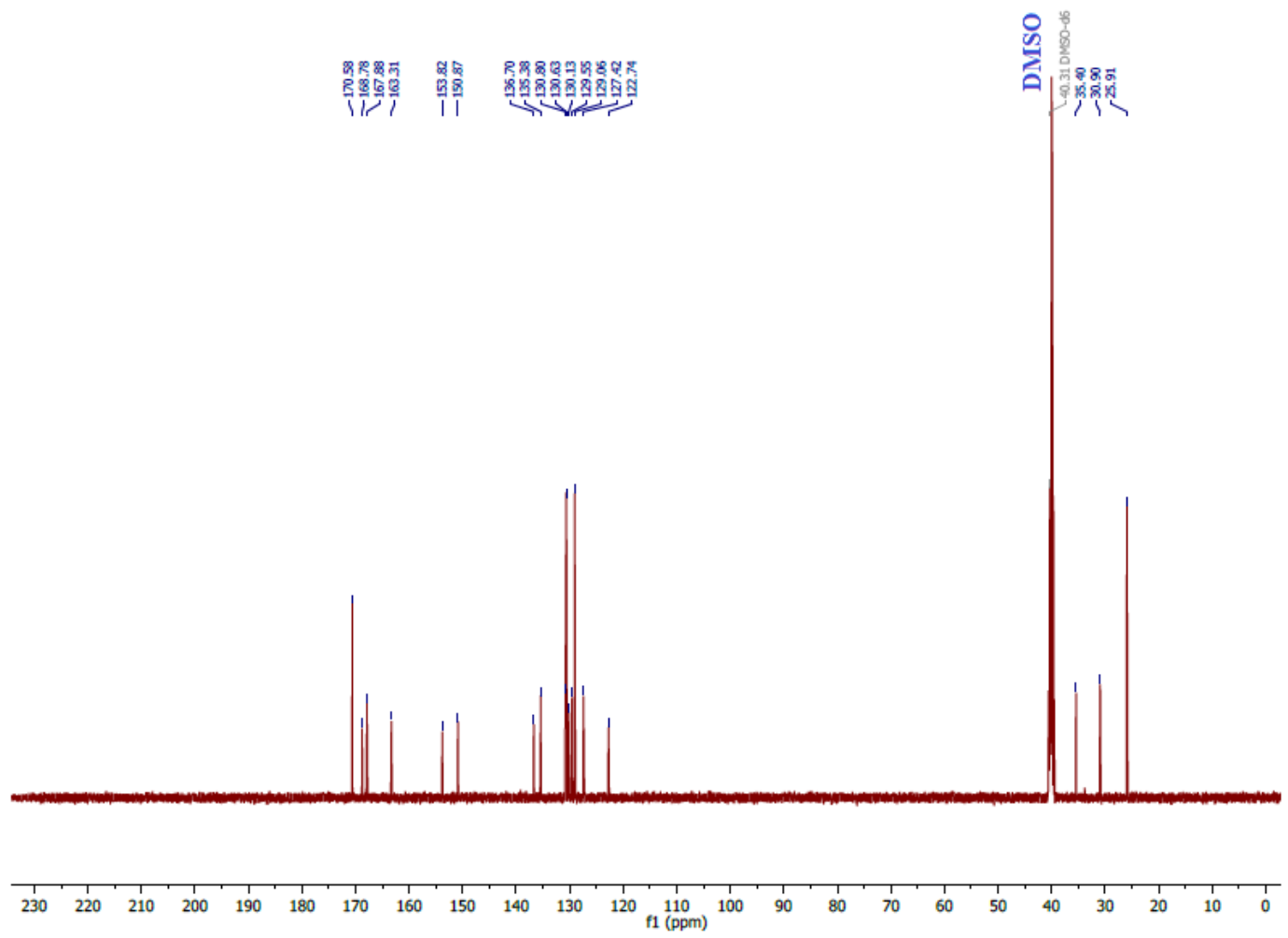

Figure S14. ${ }^{13} \mathrm{C}$ NMR spectrum of NHS-L3 (DMSO- $d_{6}$ ). 

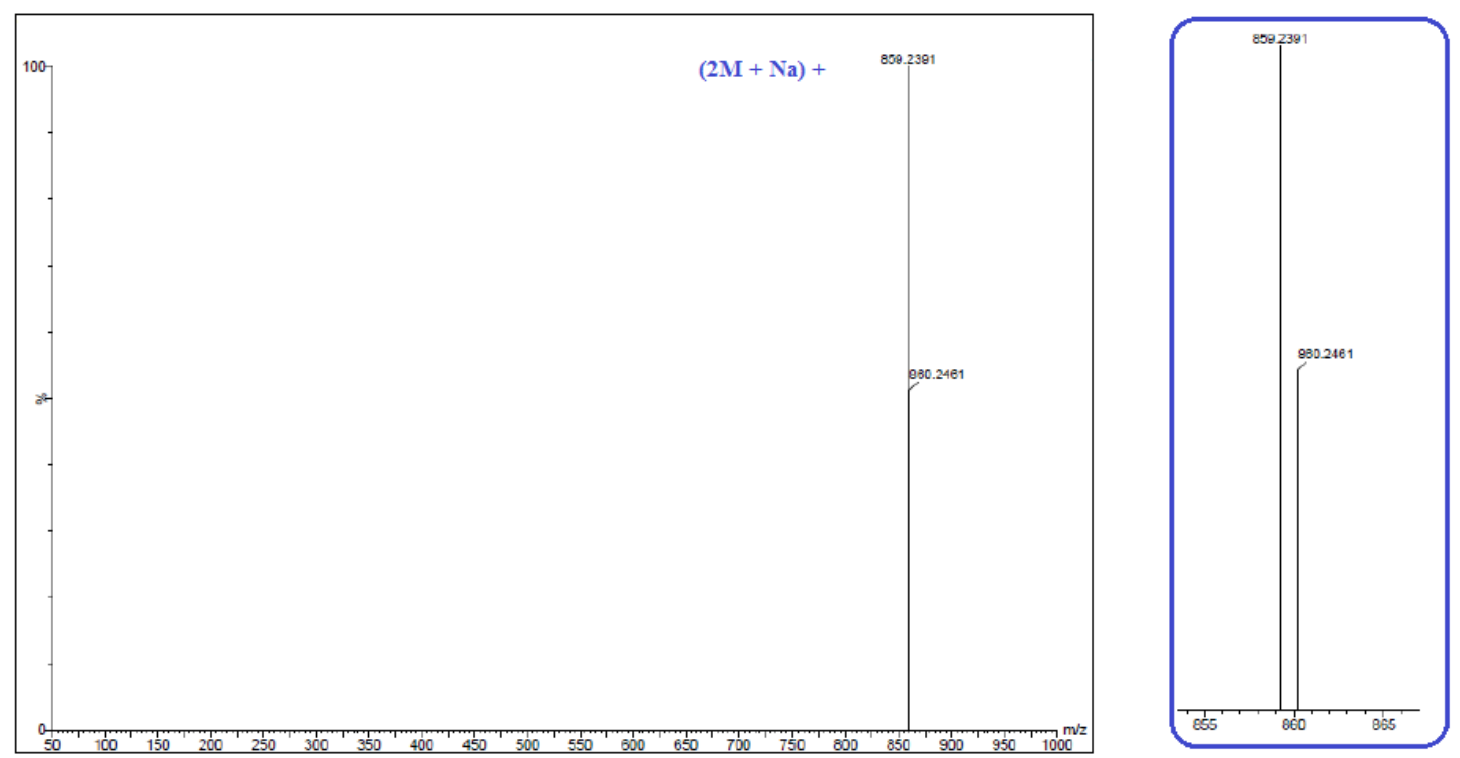

Figure S15. ESI-MS spectrum of NHS-L3.
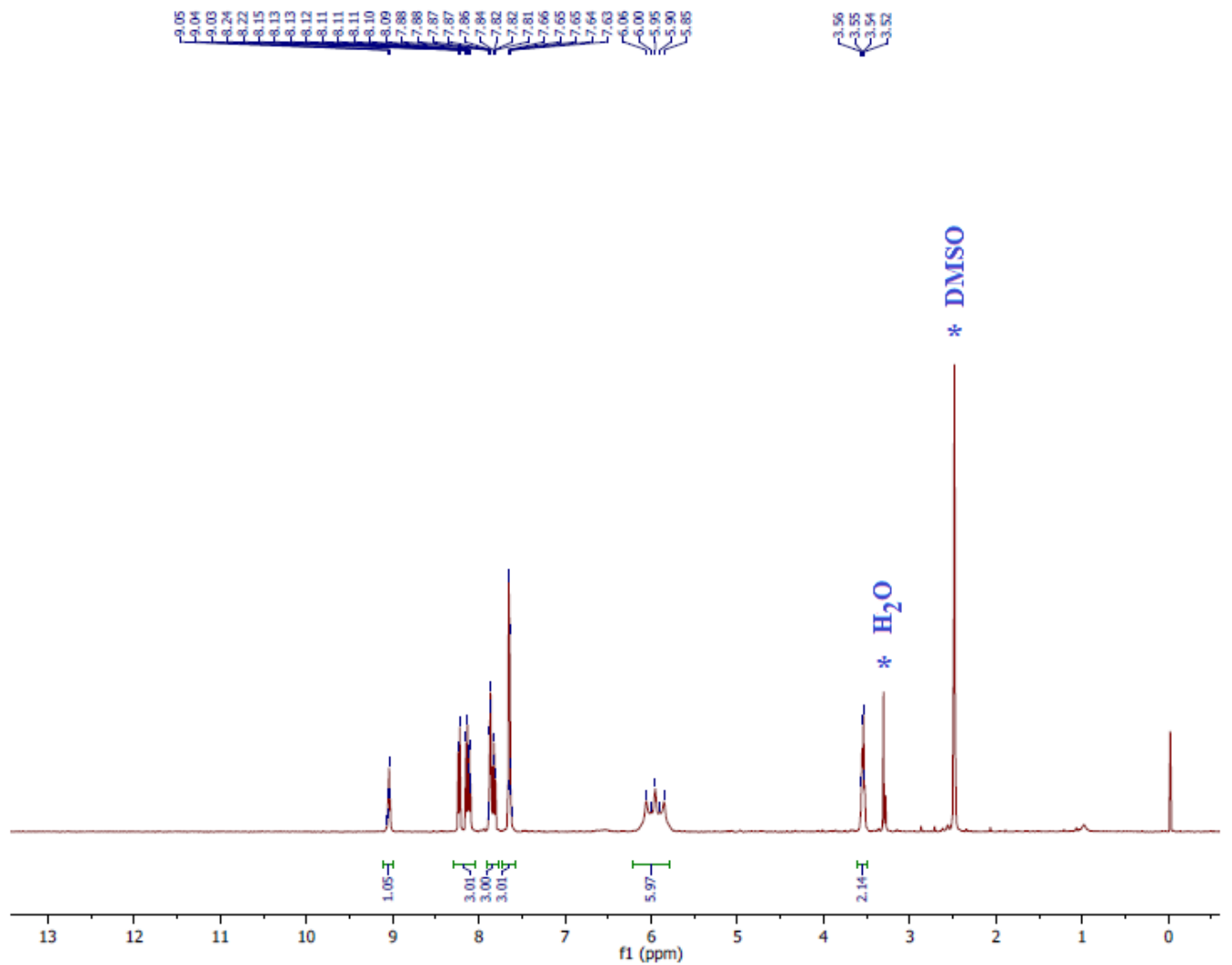

Figure S16. ${ }^{1} \mathrm{H}$ NMR spectrum of complex C-Pt1 (DMSO- $d_{6}$ ). 
DMSO *

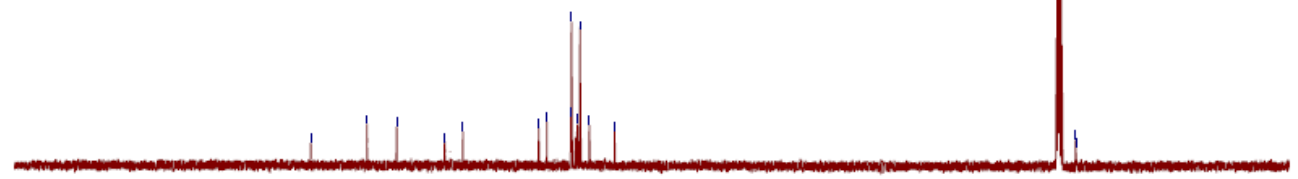

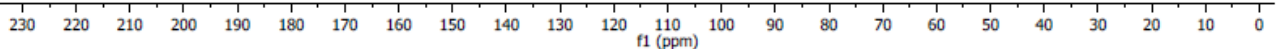

Figure S17. ${ }^{13} \mathrm{C}$ NMR spectrum of complex C-Pt1 (DMSO- $d_{6}$ ).

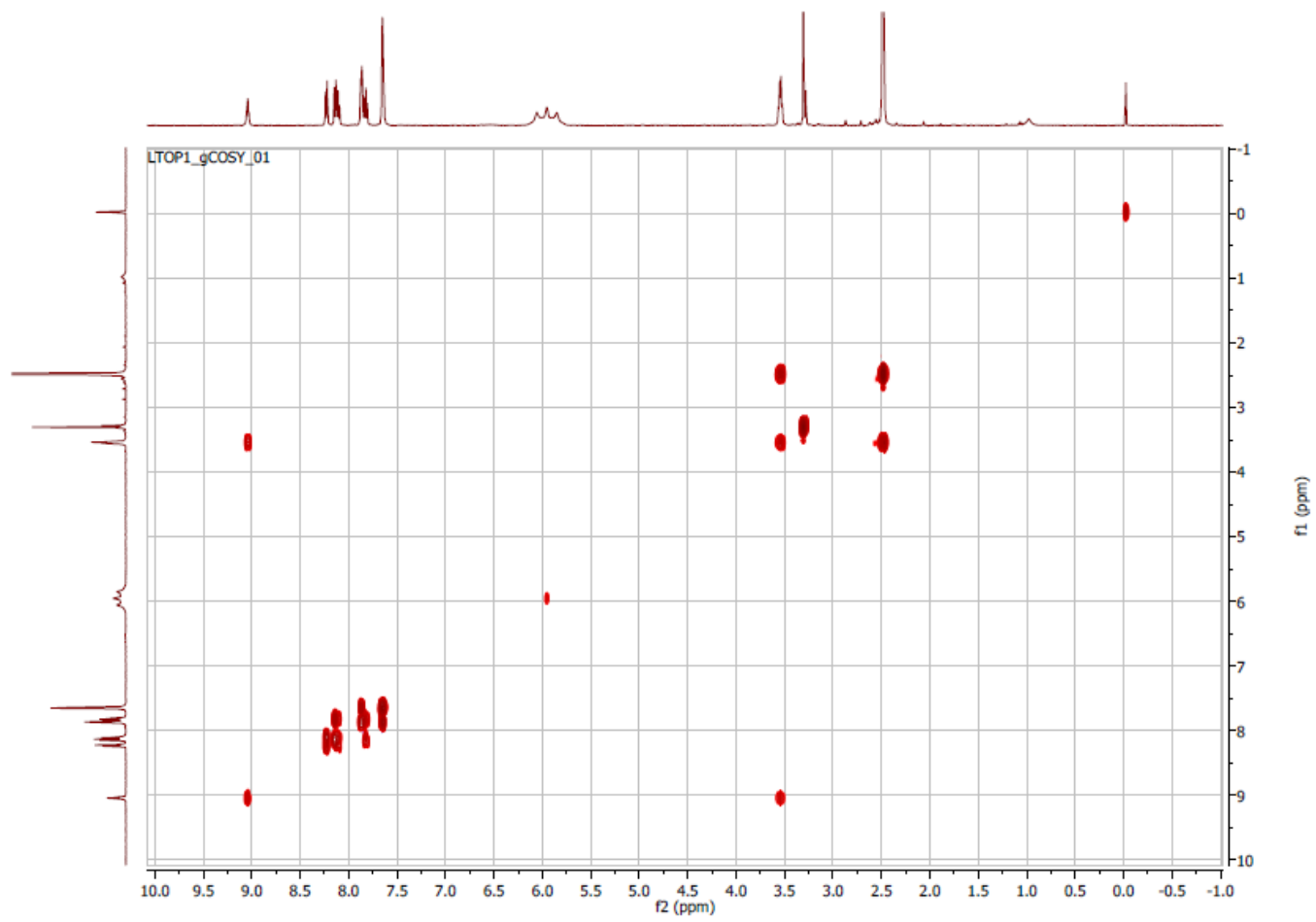

Figure S18. COSY NMR spectrum of complex C-Pt1 (DMSO- $d_{6}$ ). 


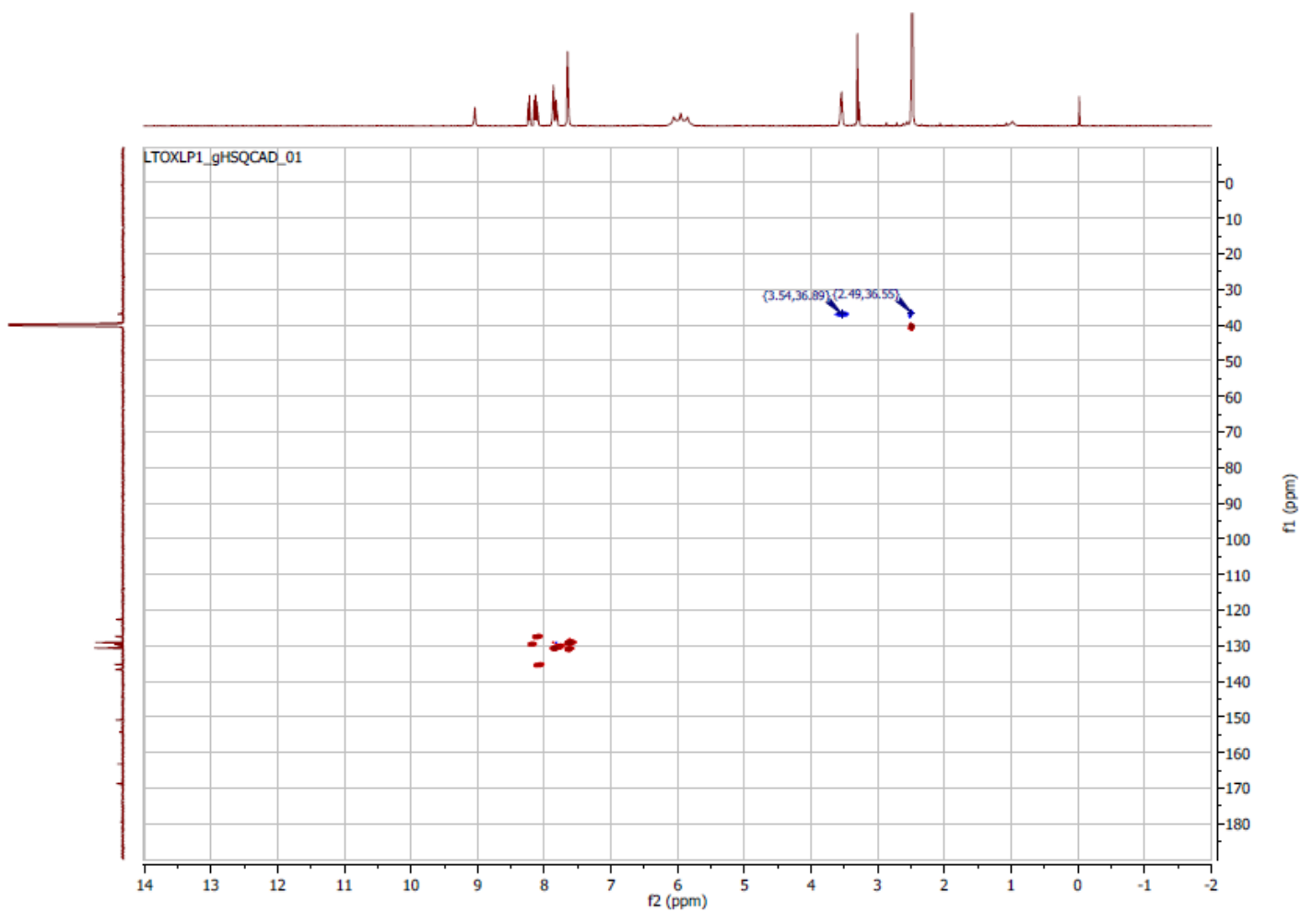

Figure S19. HSQC NMR spectrum of complex C-Pt1 (DMSO- $\left.d_{6}\right)$.

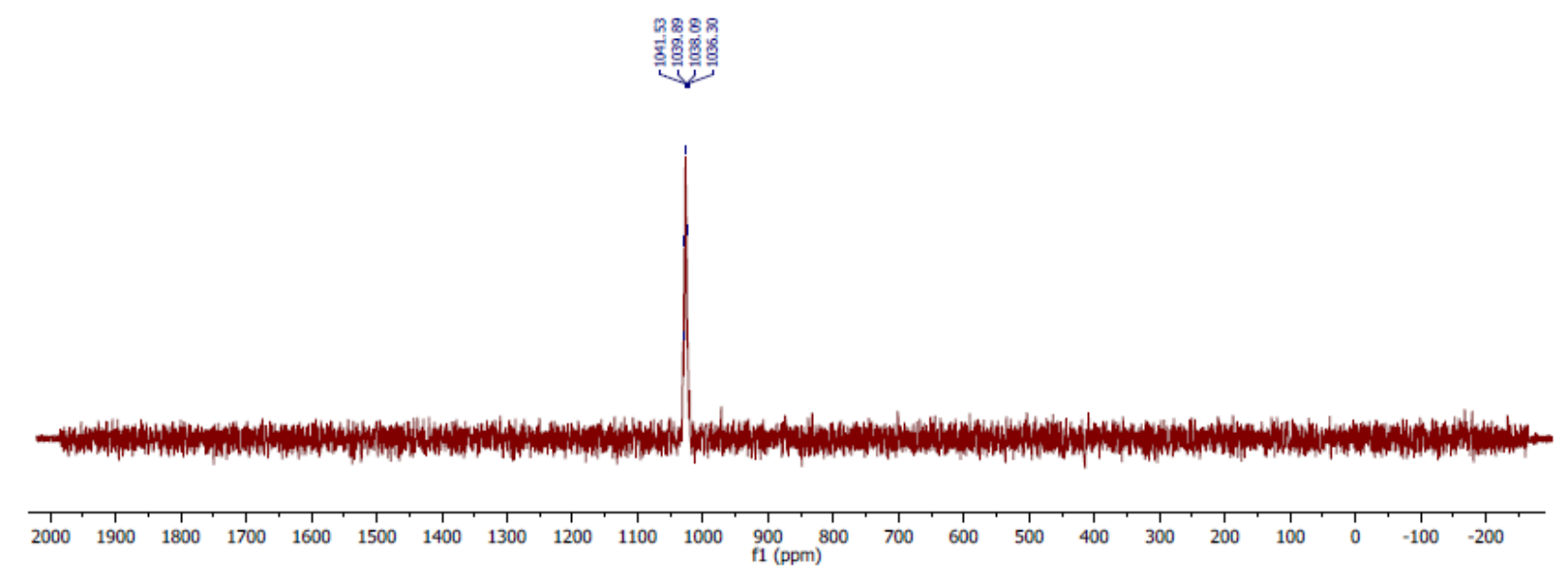

Figure S20. ${ }^{195} \mathrm{Pt}$ NMR spectrum of complex C-Pt1 (DMF insert $\left.\mathrm{D}_{2} \mathrm{O}\right)$. 


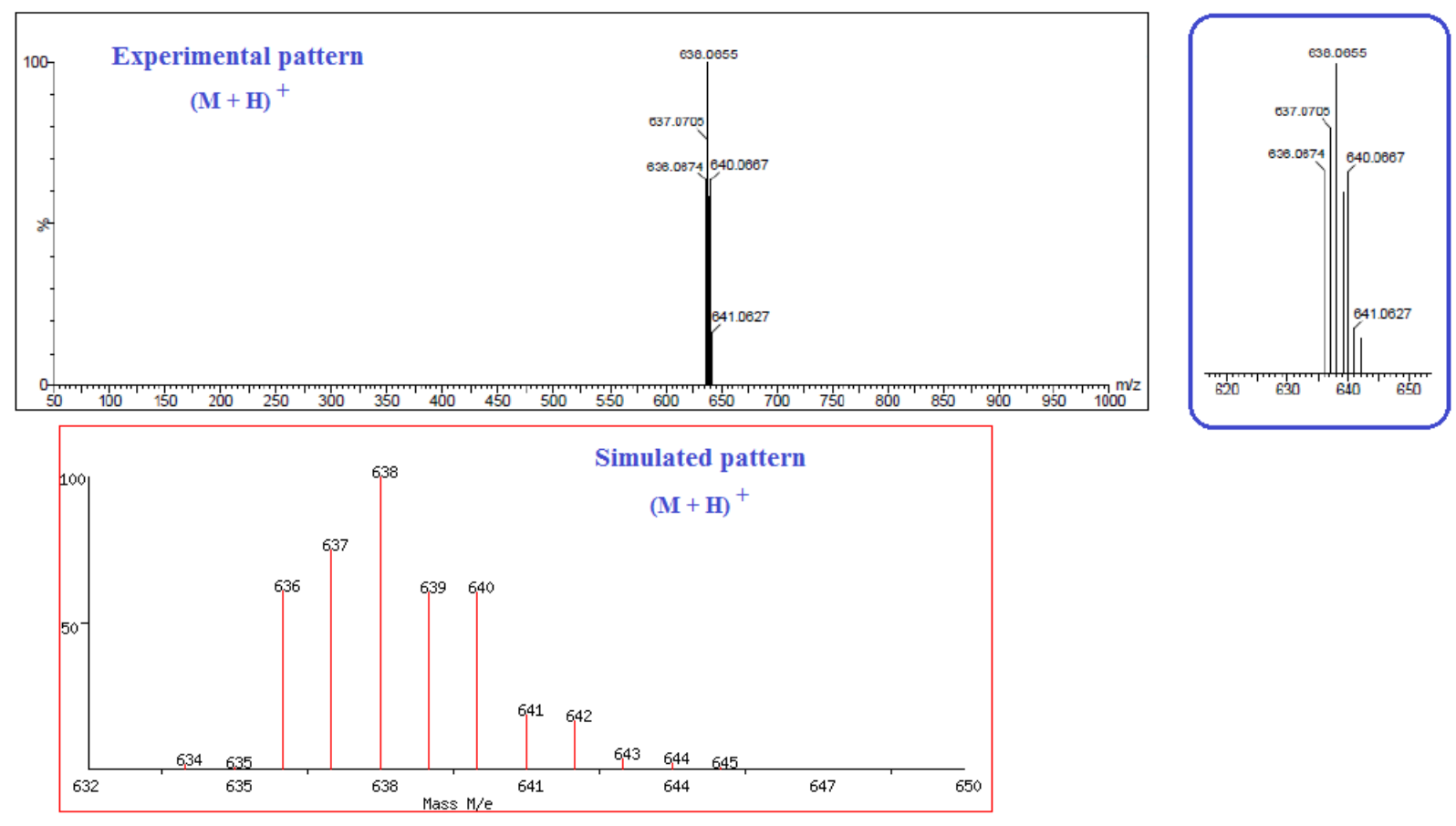

Figure S21. ESI-MS spectrum of complex C-Pt1.

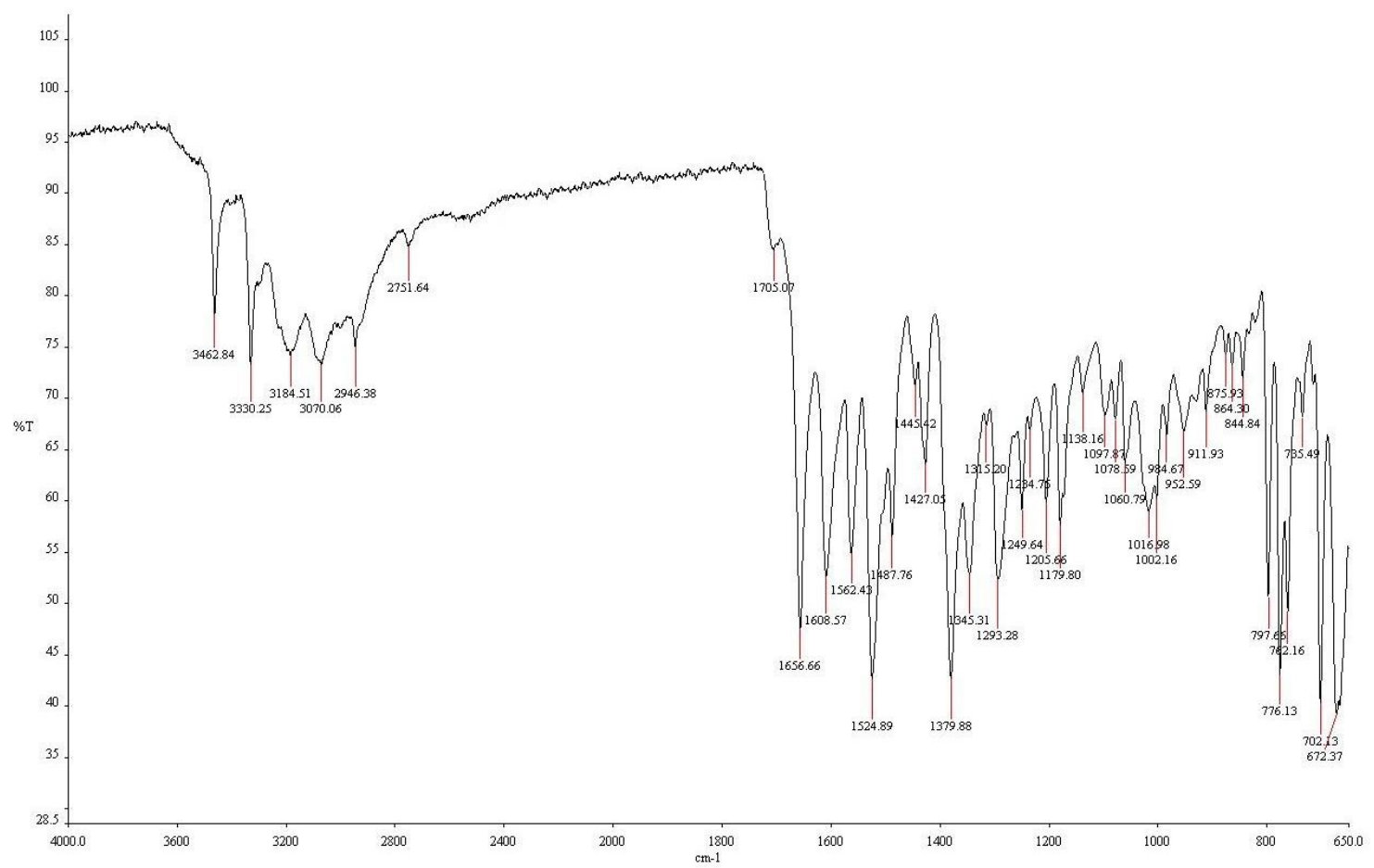

Figure S22. IR spectrum of complex C-Pt1. 

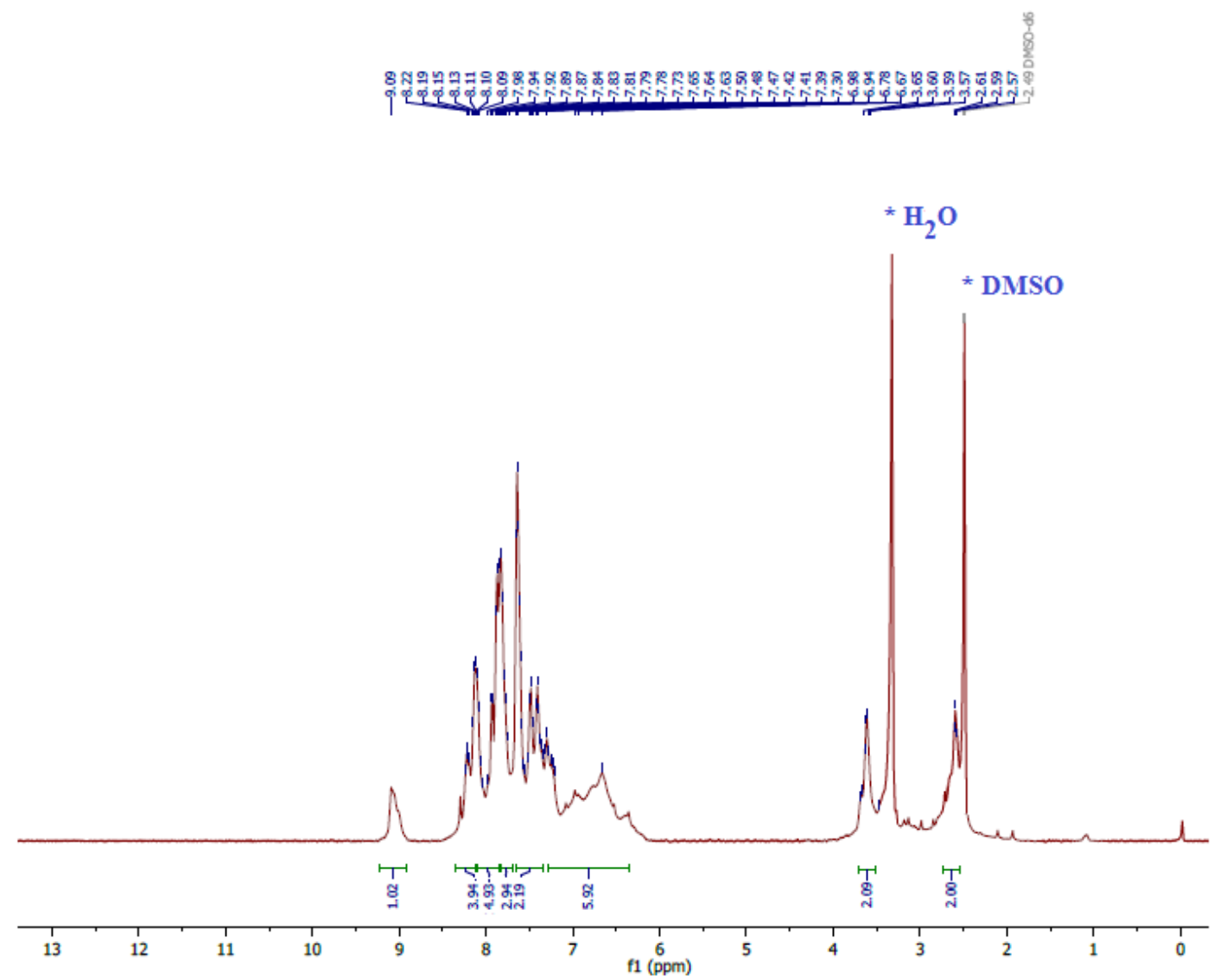

Figure S23. ${ }^{1} \mathrm{H}$ NMR spectrum of complex C-Pt2 (DMSO- $d_{6}$ ). 


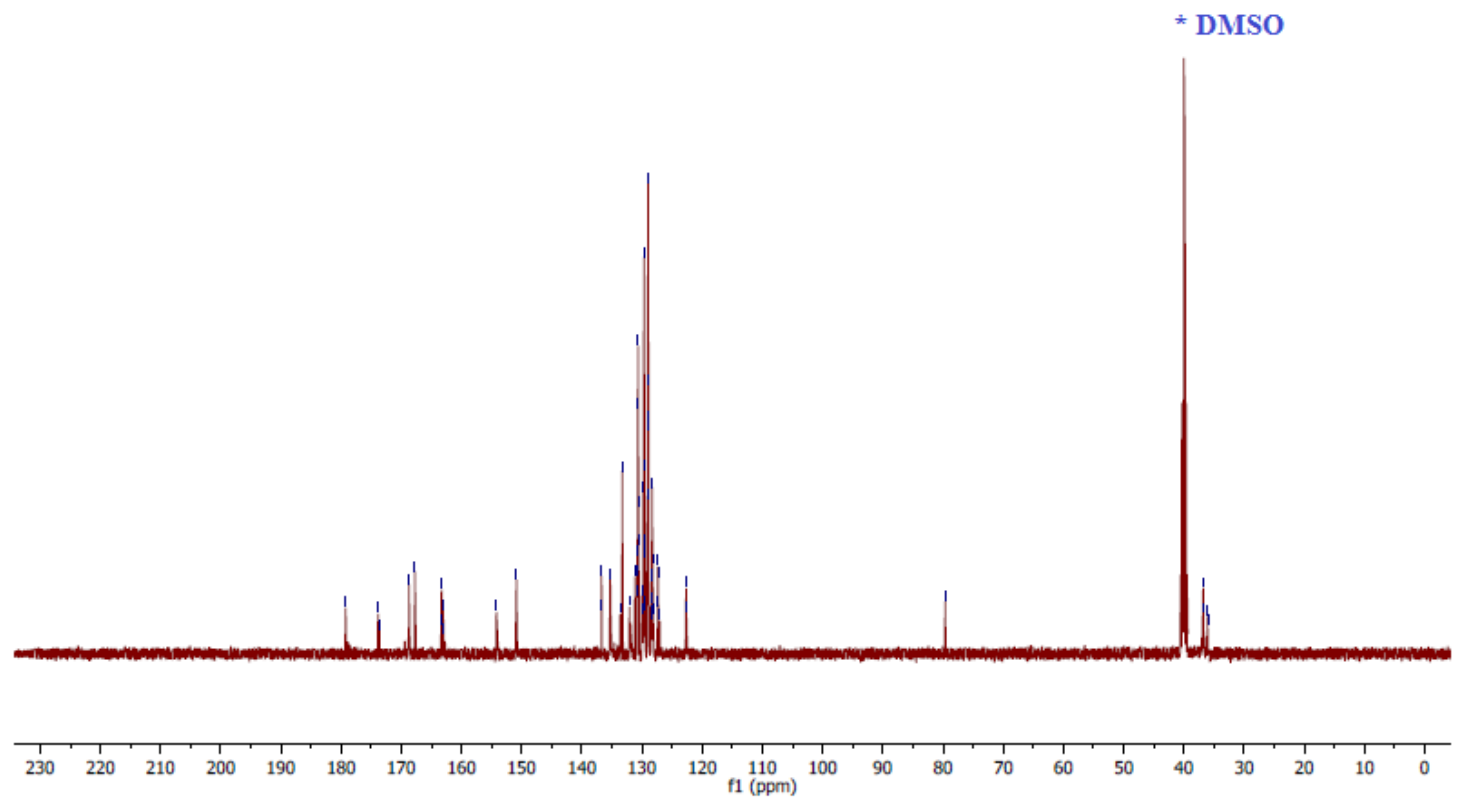

Figure S24. ${ }^{13} \mathrm{C}$ NMR spectrum of complex C-Pt2 (DMSO- $\left.d_{6}\right)$. 


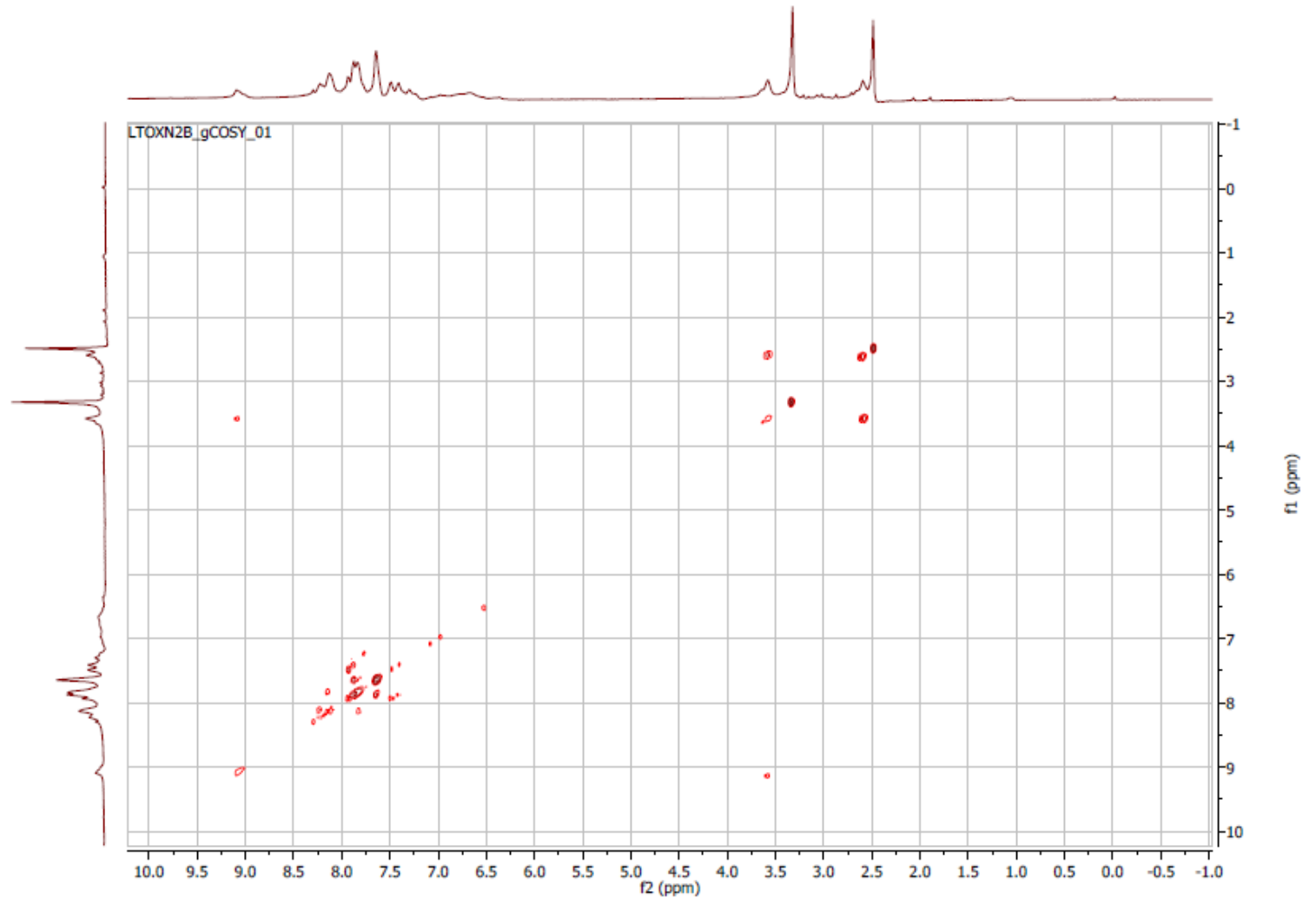

Figure S25. COSY NMR spectrum of complex C-Pt2 (DMSO- $d_{6}$ ).

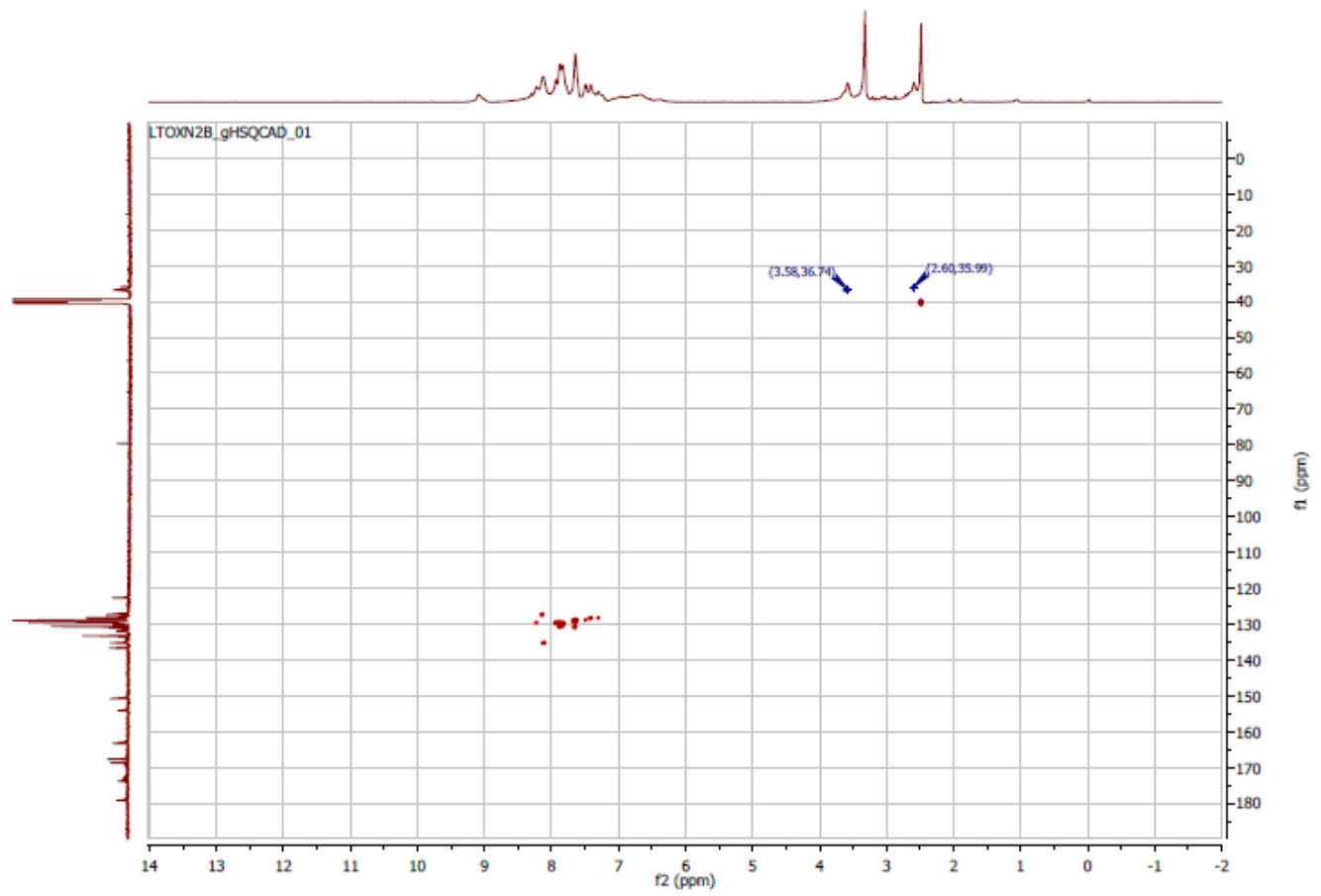

Figure S26. HSQC NMR spectrum of complex C-Pt2 (DMSO- $d_{6}$ ). 


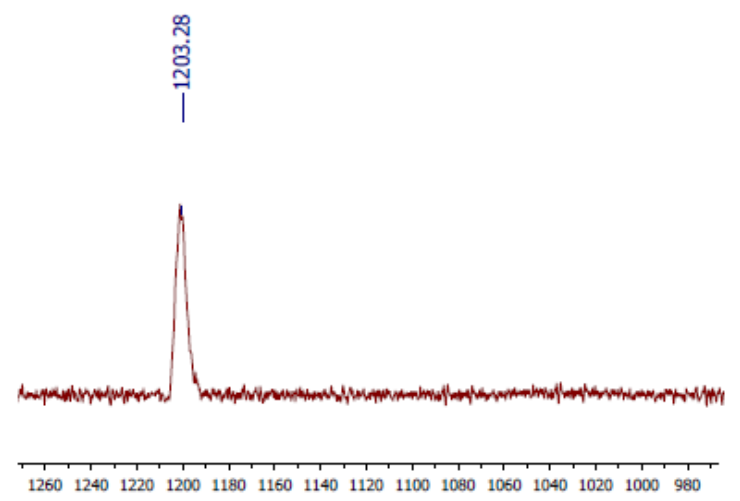

Figure S27. ${ }^{195} \mathrm{Pt}$ NMR spectrum of complex C-Pt2 (DMF insert $\mathrm{D}_{2} \mathrm{O}$ ).
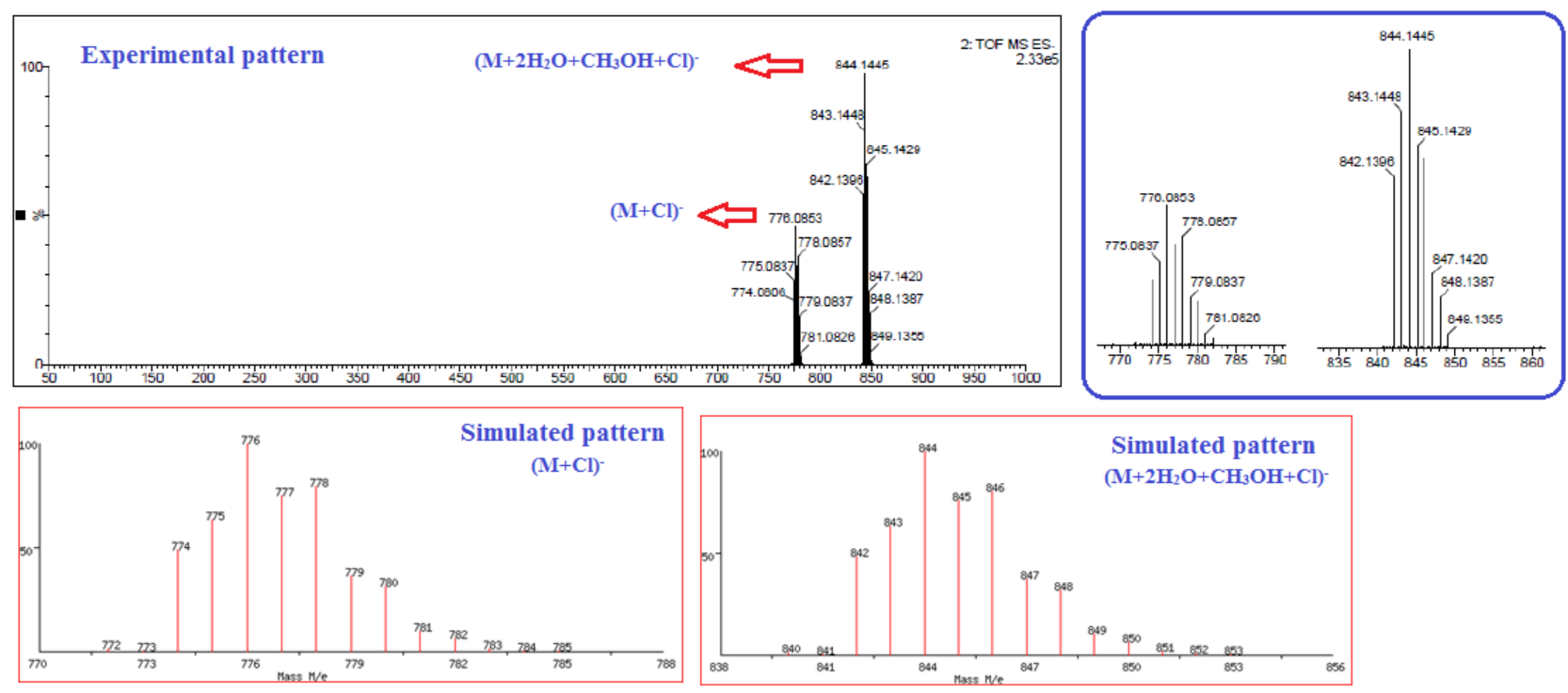

Figure S28. ESI-MS spectrum of complex C-Pt2. 


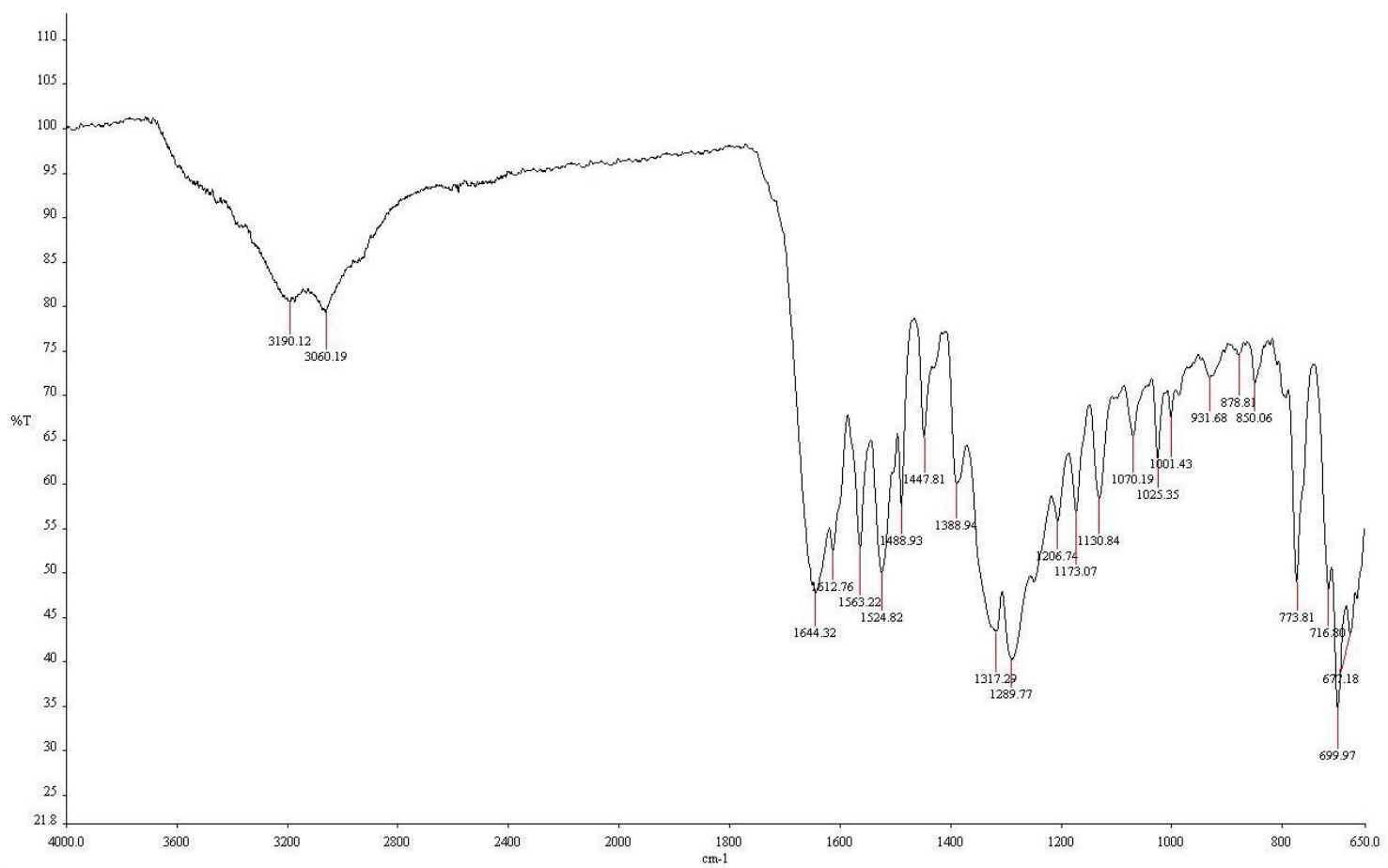

Figure S29. IR spectrum of complex C-Pt2.

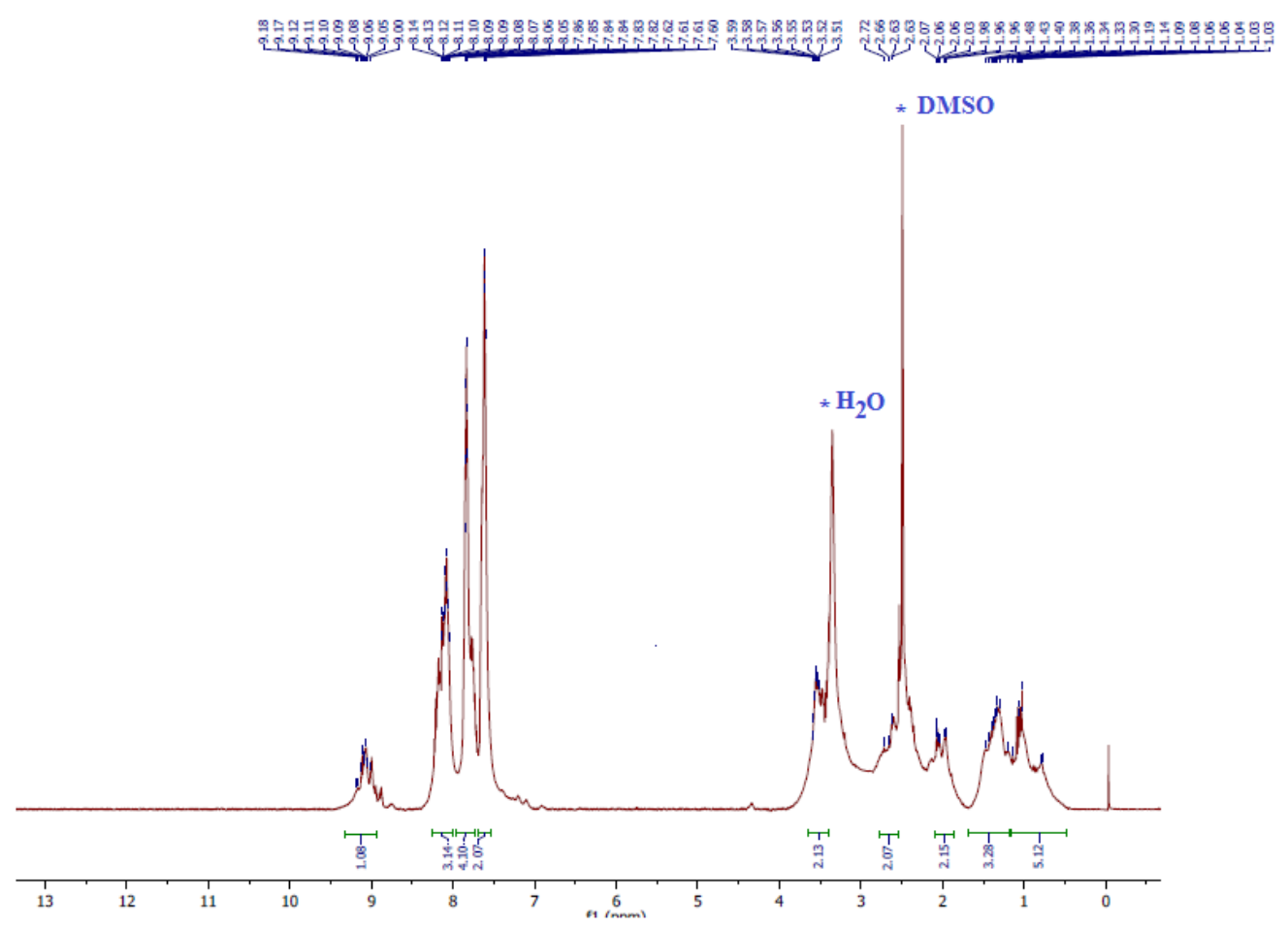

Figure S30. ${ }^{1} \mathrm{H}$ NMR spectrum of complex C-Pt3 (DMSO- $d_{6}$ ). 


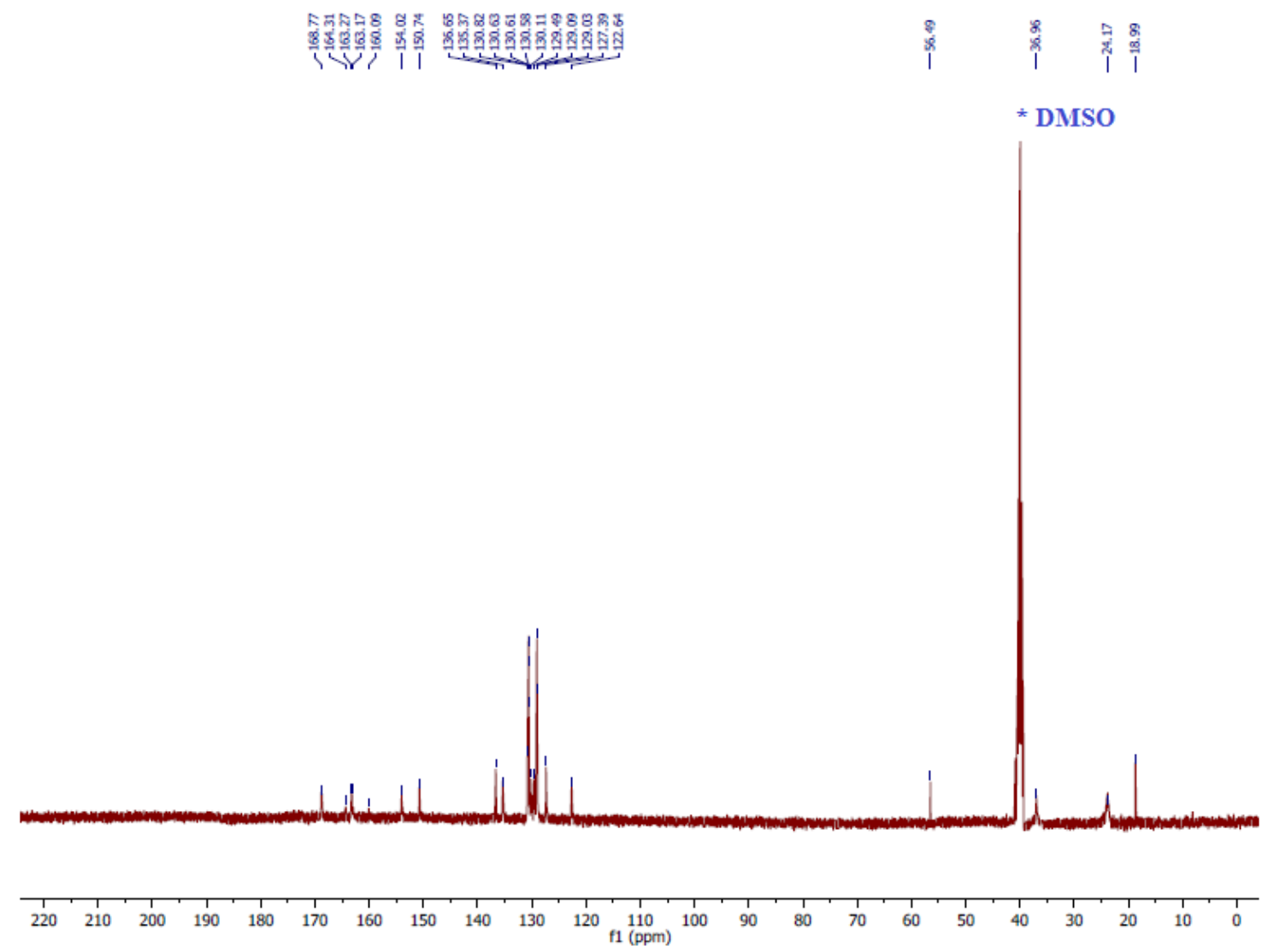

Figure S31. ${ }^{13} \mathrm{C}$ NMR spectrum of complex C-Pt3 (DMSO- $d_{6}$ ). 


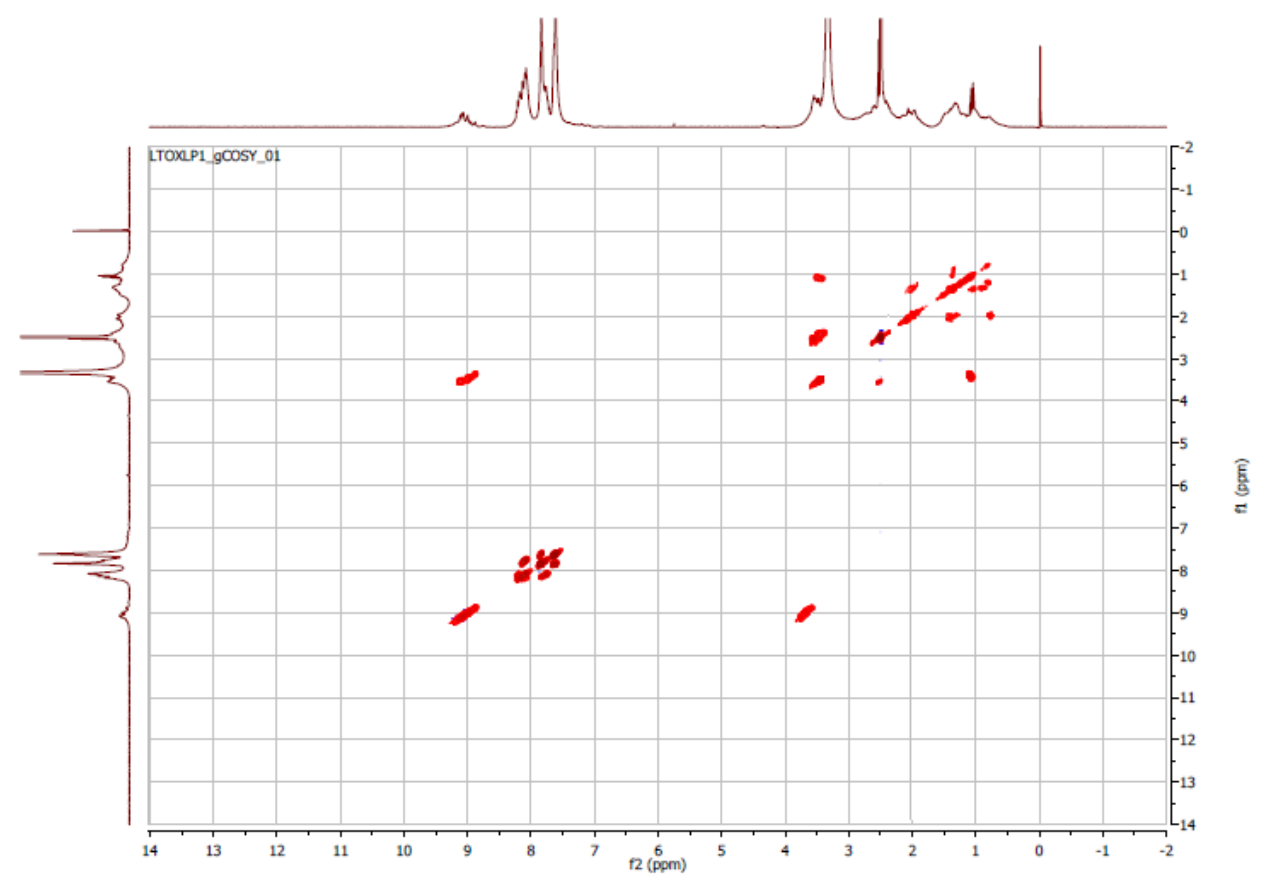

Figure S32. COSY NMR spectrum of complex C-Pt3 (DMSO- $\left.d_{6}\right)$.

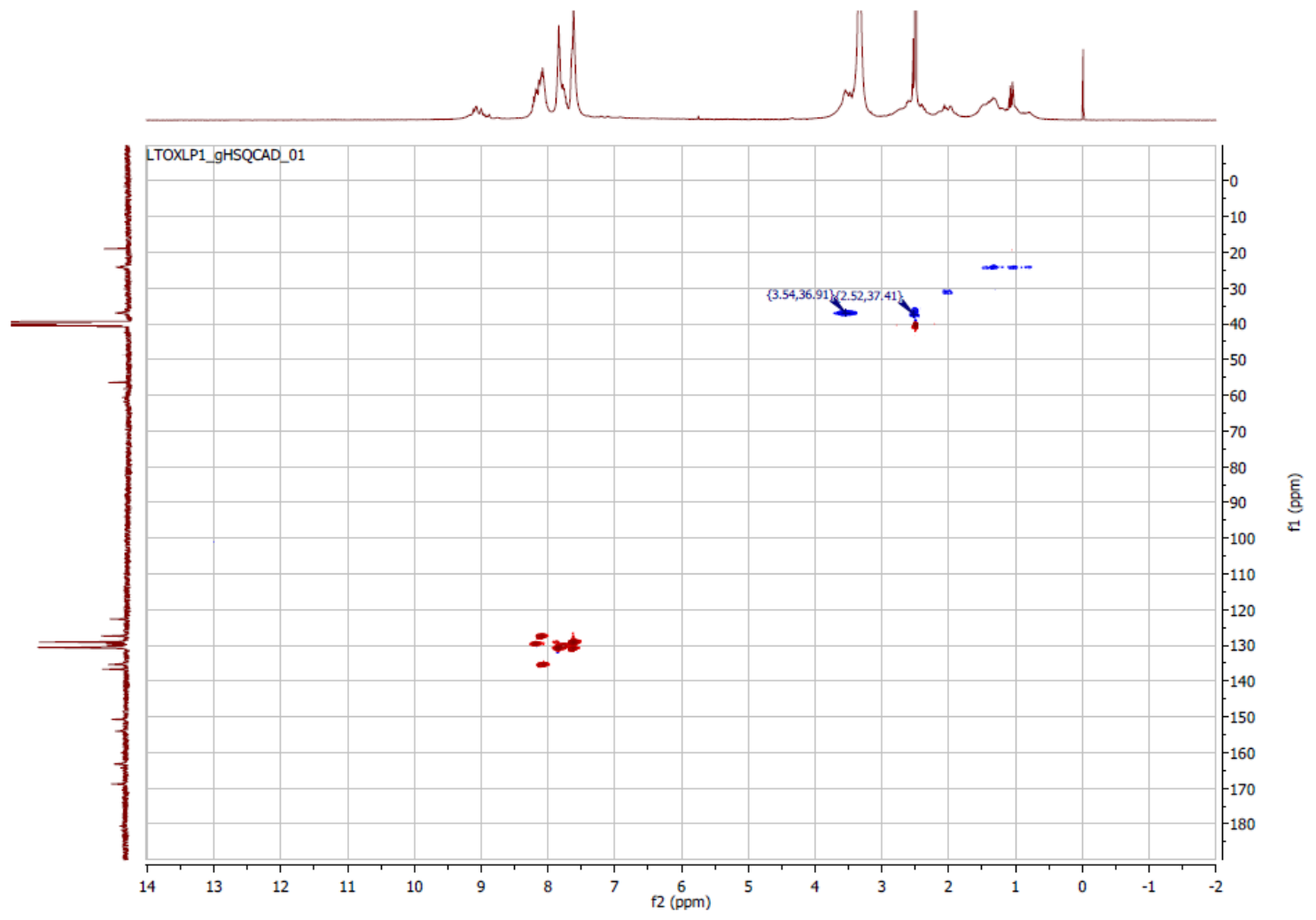

Figure S33. HSQC NMR spectrum of complex C-Pt3 (DMSO- $\left.d_{6}\right)$. 


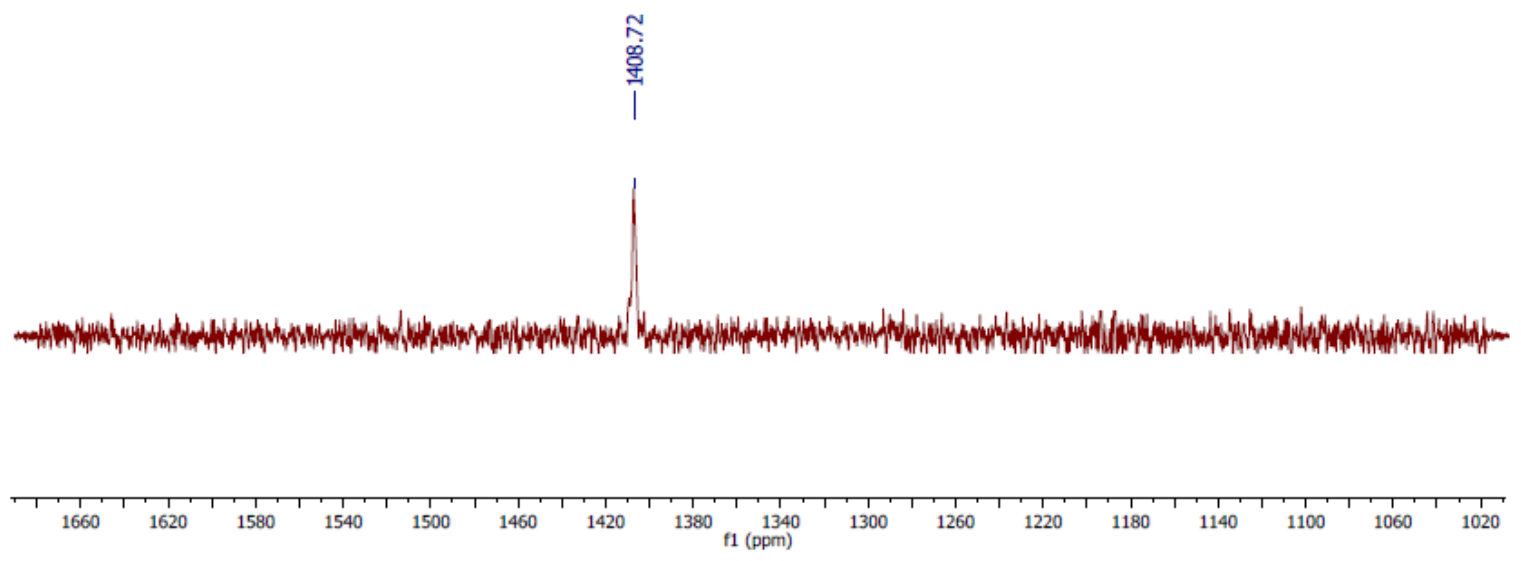

Figure S34. ${ }^{195} \mathrm{Pt}$ NMR spectrum of complex C-Pt3 (DMF insert $\mathrm{D}_{2} \mathrm{O}$ ).
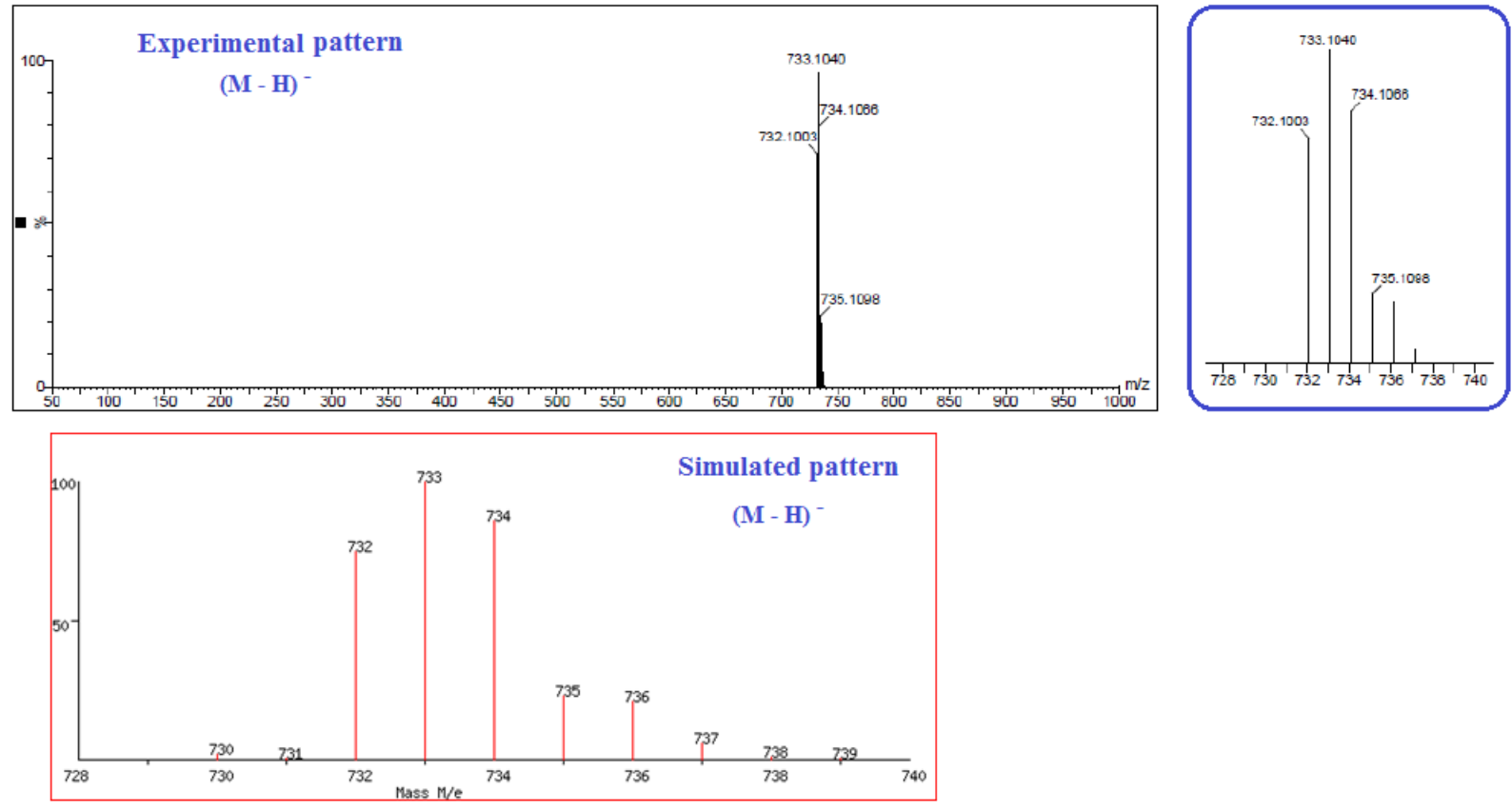

Figure S35. ESI-MS spectrum of complex C-Pt3. 


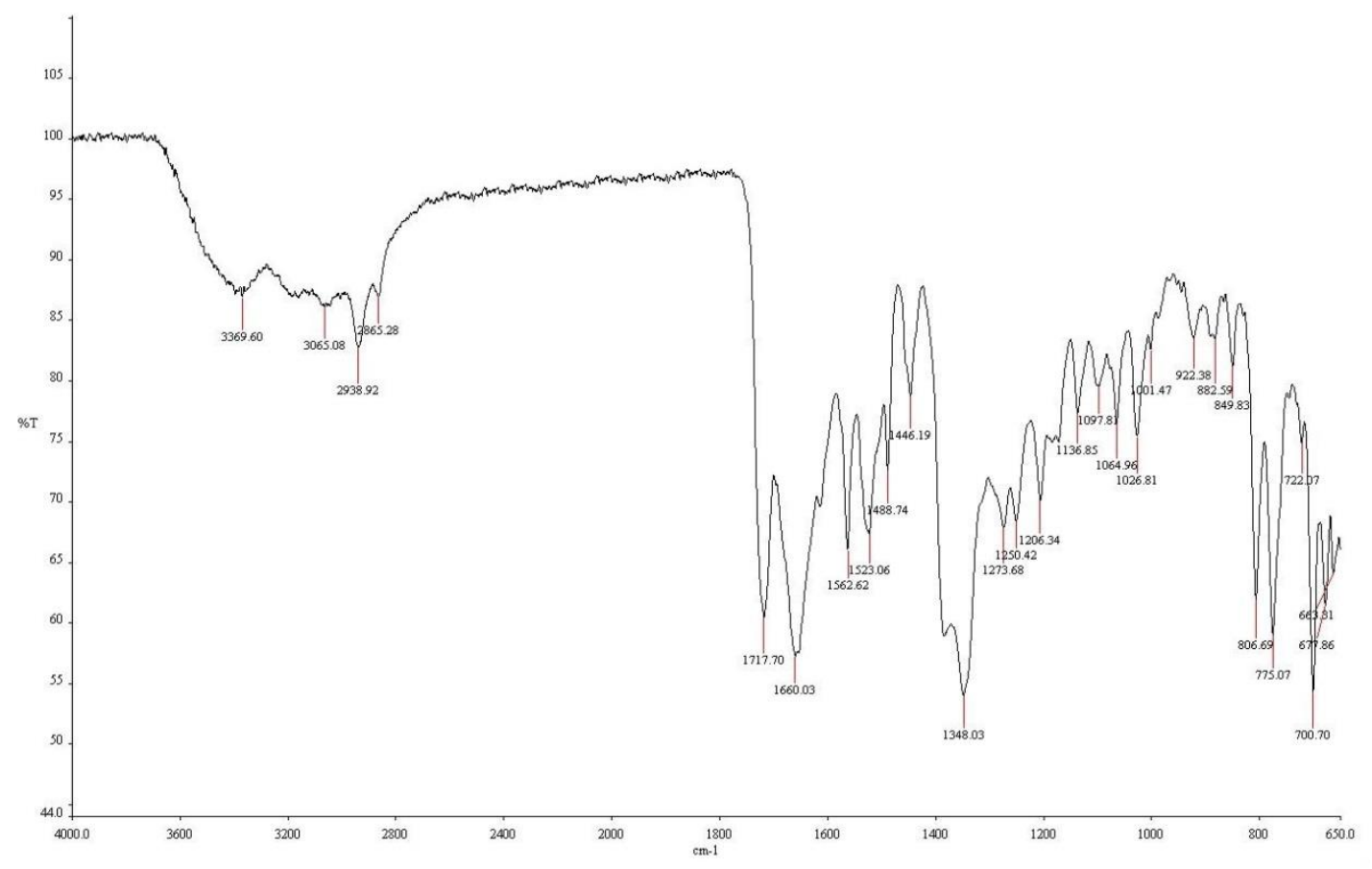

Figure S36. IR spectrum of complex C-Pt3.

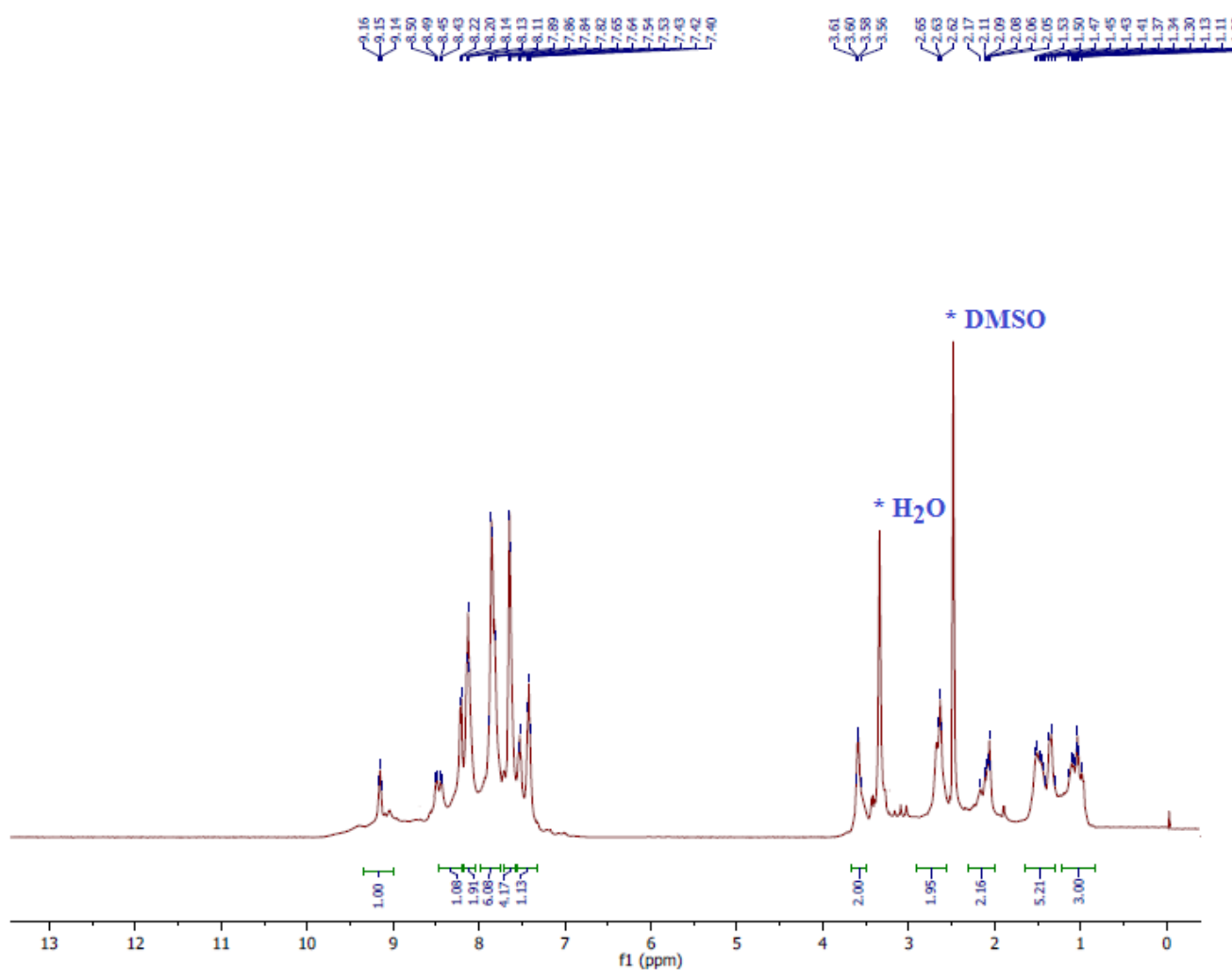

Figure S37. ${ }^{1} \mathrm{H}$ NMR spectrum of complex C-Pt4 (DMSO- $d_{6}$ ). 


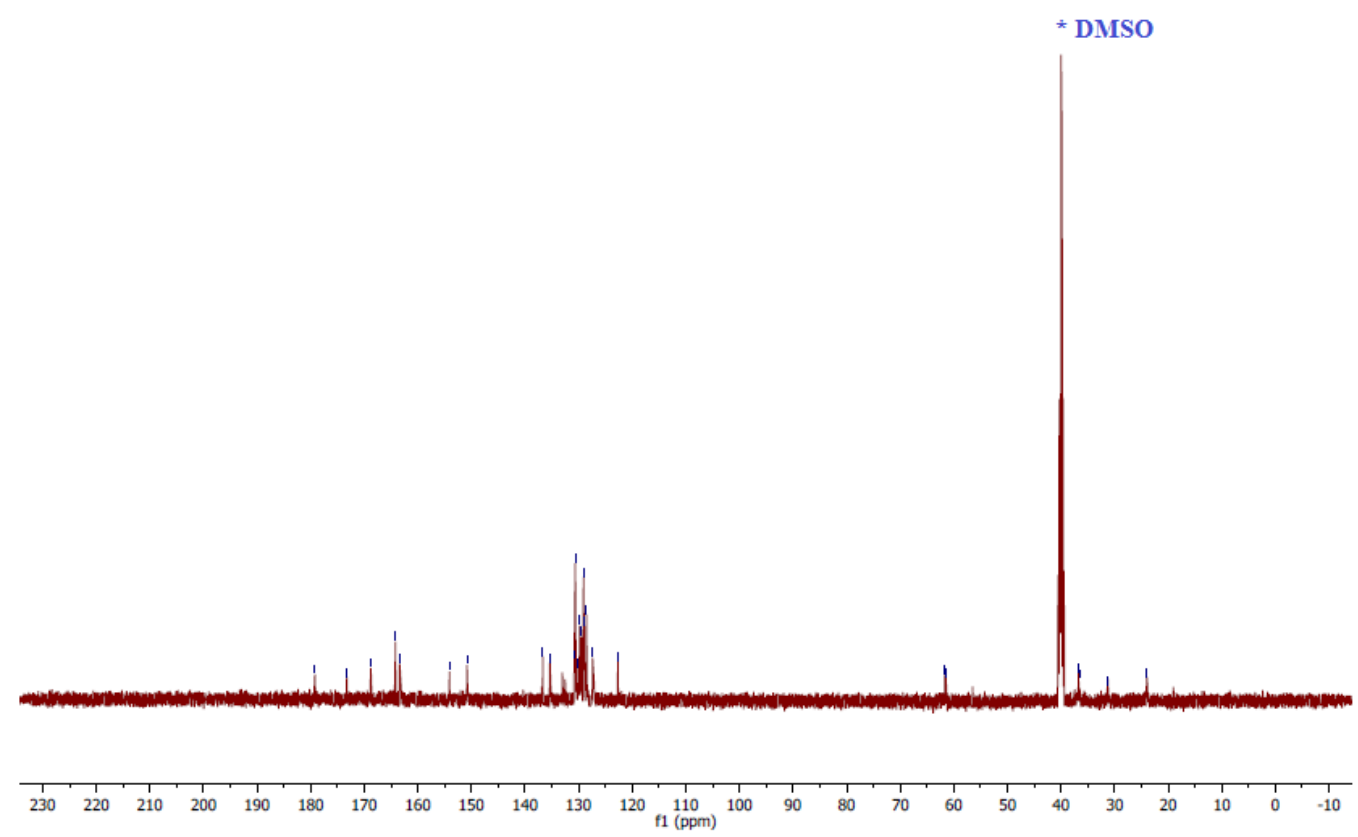

Figure S38. ${ }^{13} \mathrm{C}$ NMR spectrum of complex C-Pt4 (DMSO- $d_{6}$ ).

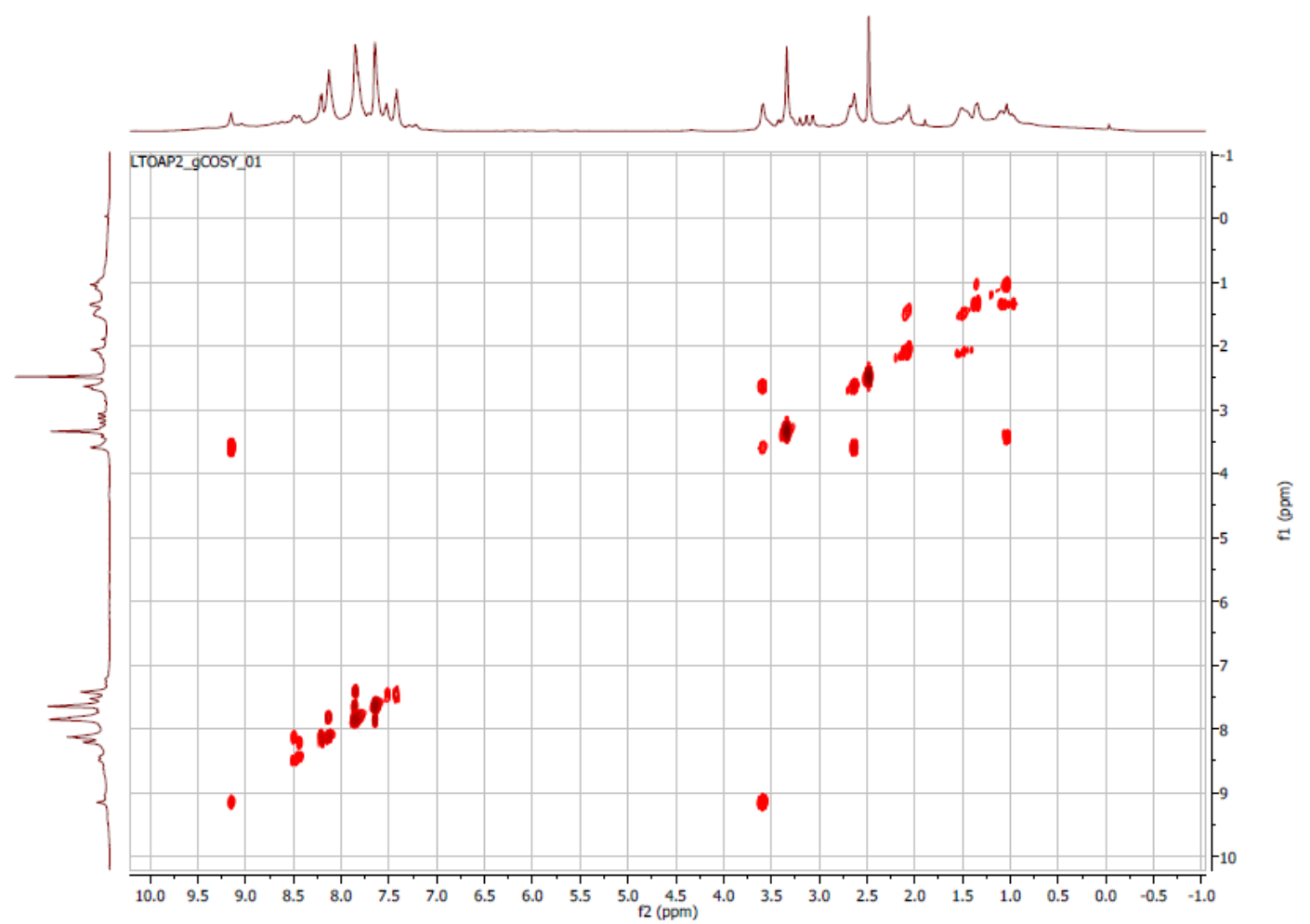

Figure S39. COSY NMR spectrum of complex C-Pt4 (DMSO- $d_{6}$ ). 


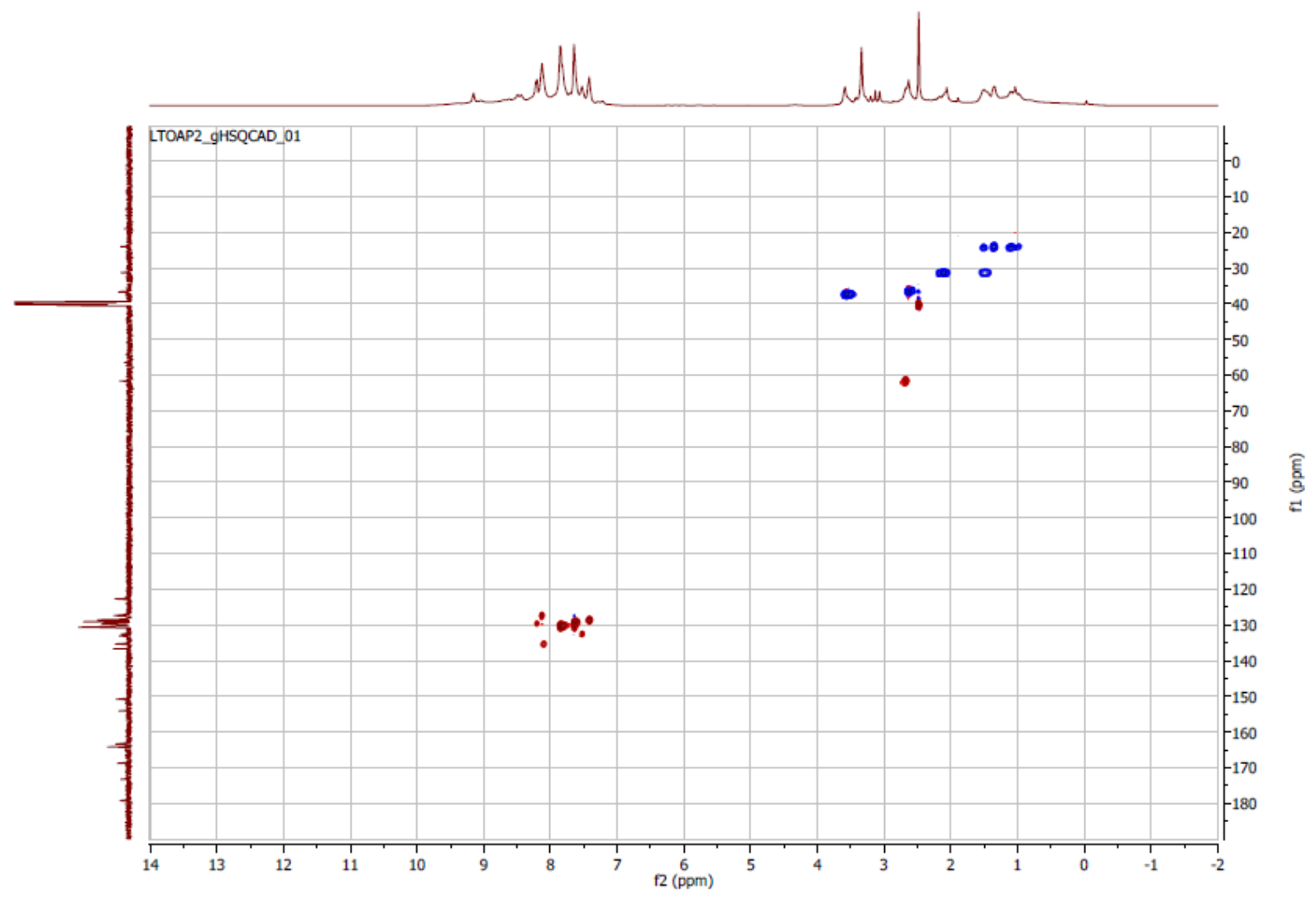

Figure S40. HSQC NMR spectrum of complex C-Pt4 (DMSO- $d_{6}$ ).

i

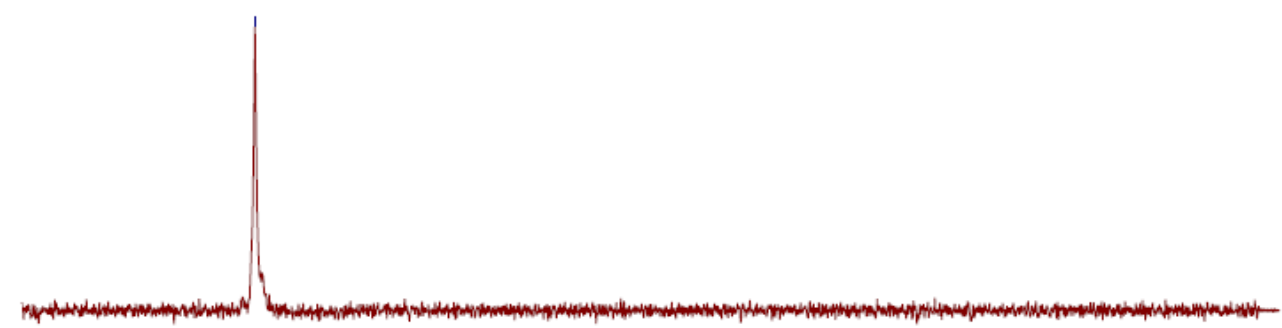

Figure S41. ${ }^{195} \mathrm{Pt}$ NMR spectrum of complex C-Pt4 (DMF insert $\left.\mathrm{D}_{2} \mathrm{O}\right)$. 


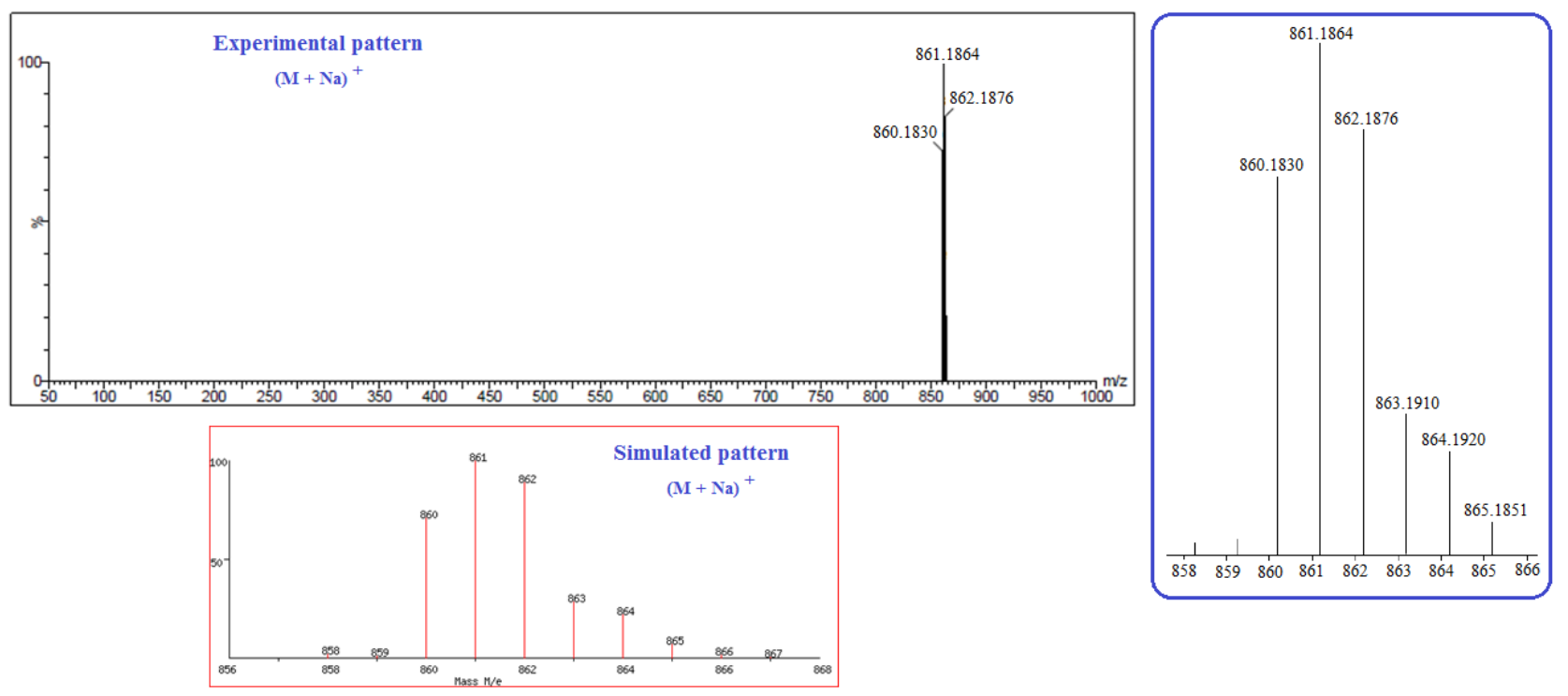

Figure S42. ESI-MS spectrum of complex C-Pt4.

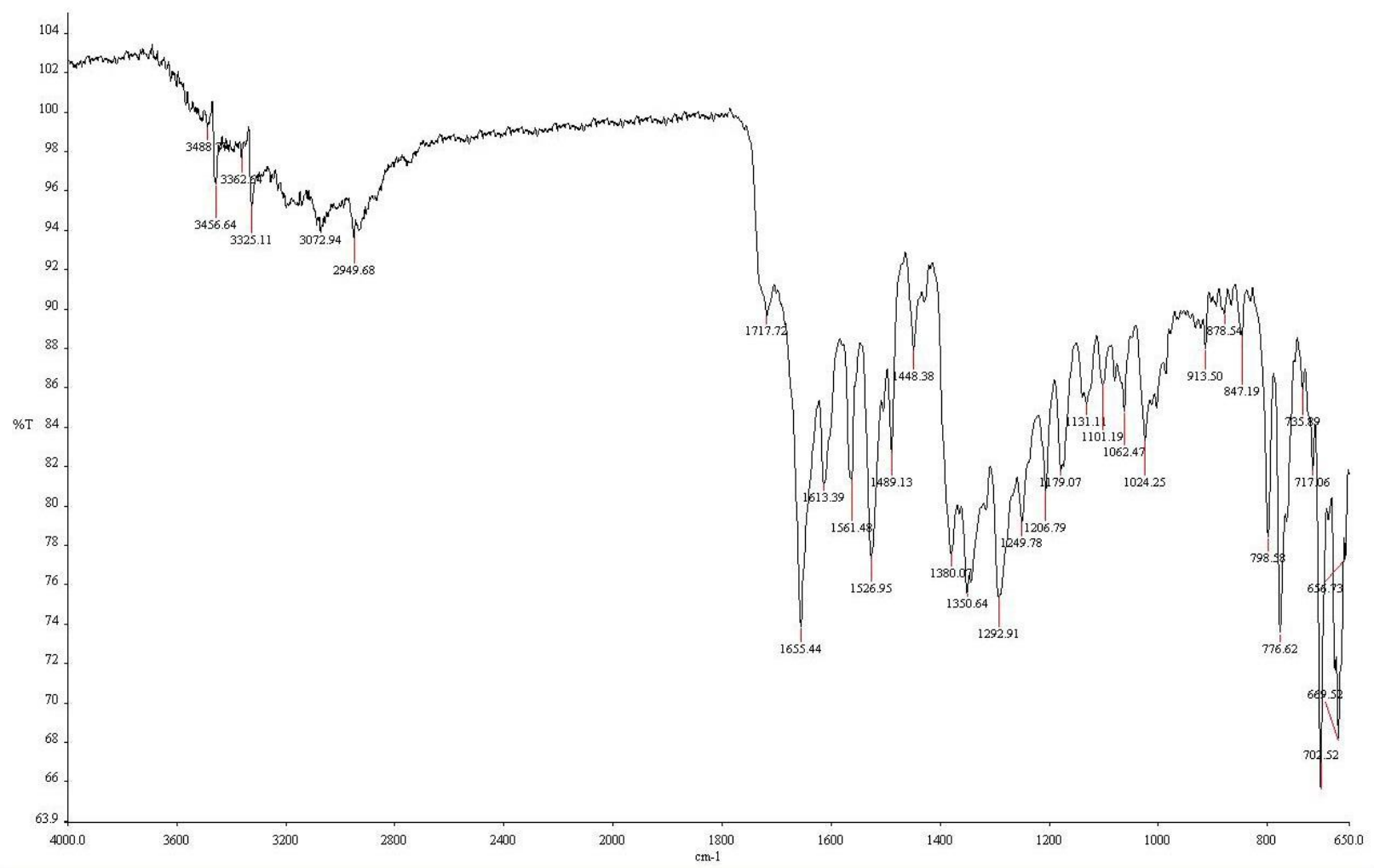

Figure S43. IR spectrum of complex C-Pt4. 

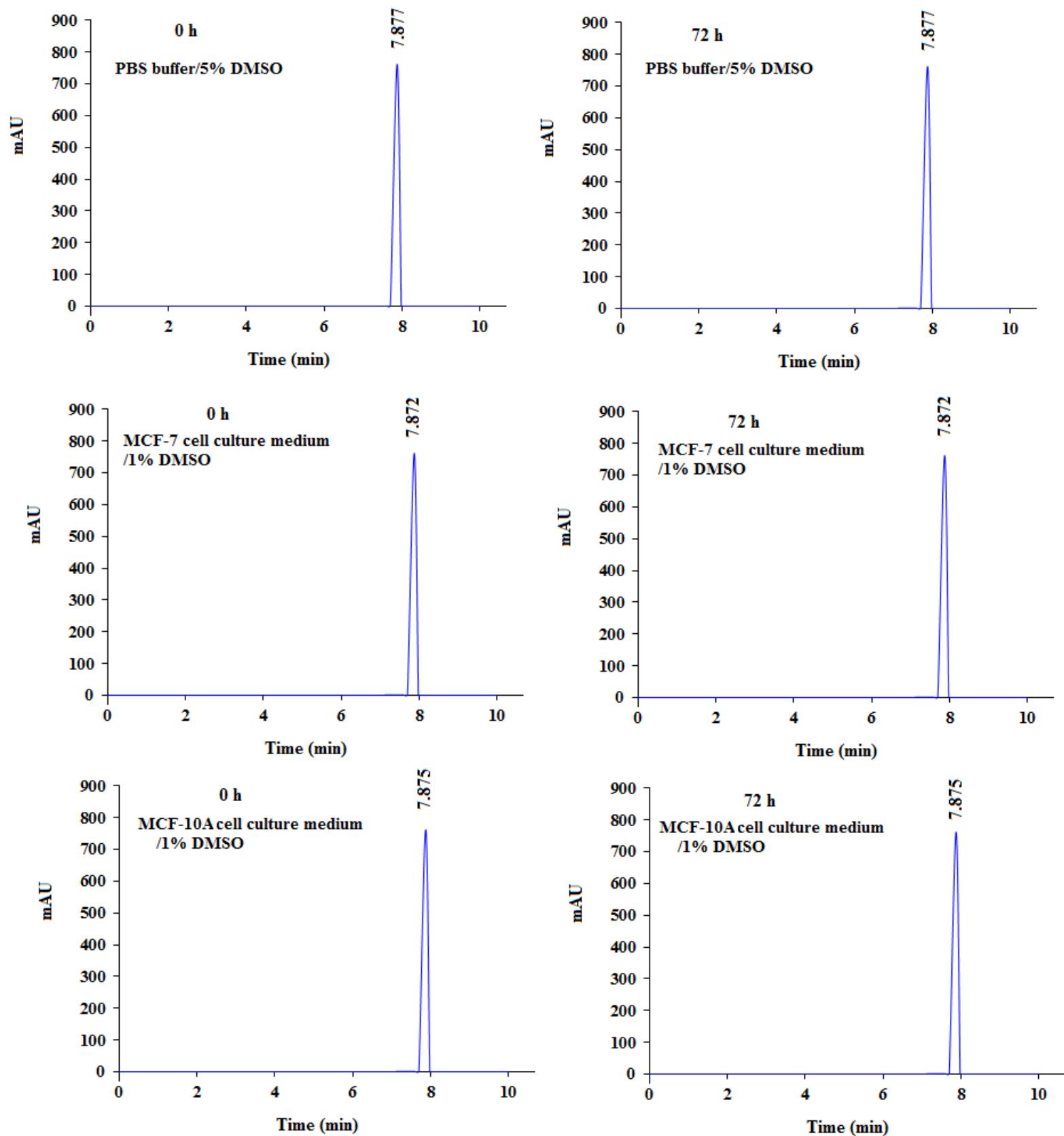

Figure S44. HPLC chromatograms of $\mathbf{L 3}$ in freshly prepared PBS buffer/5\% DMSO solution, 1\%DMSO/MCF-7 and 1\%DMSO/MCF-10A cell culture medium recorded after $0 \mathrm{~h}$ and $72 \mathrm{~h}$ incubation at $37^{\circ} \mathrm{C}$. 

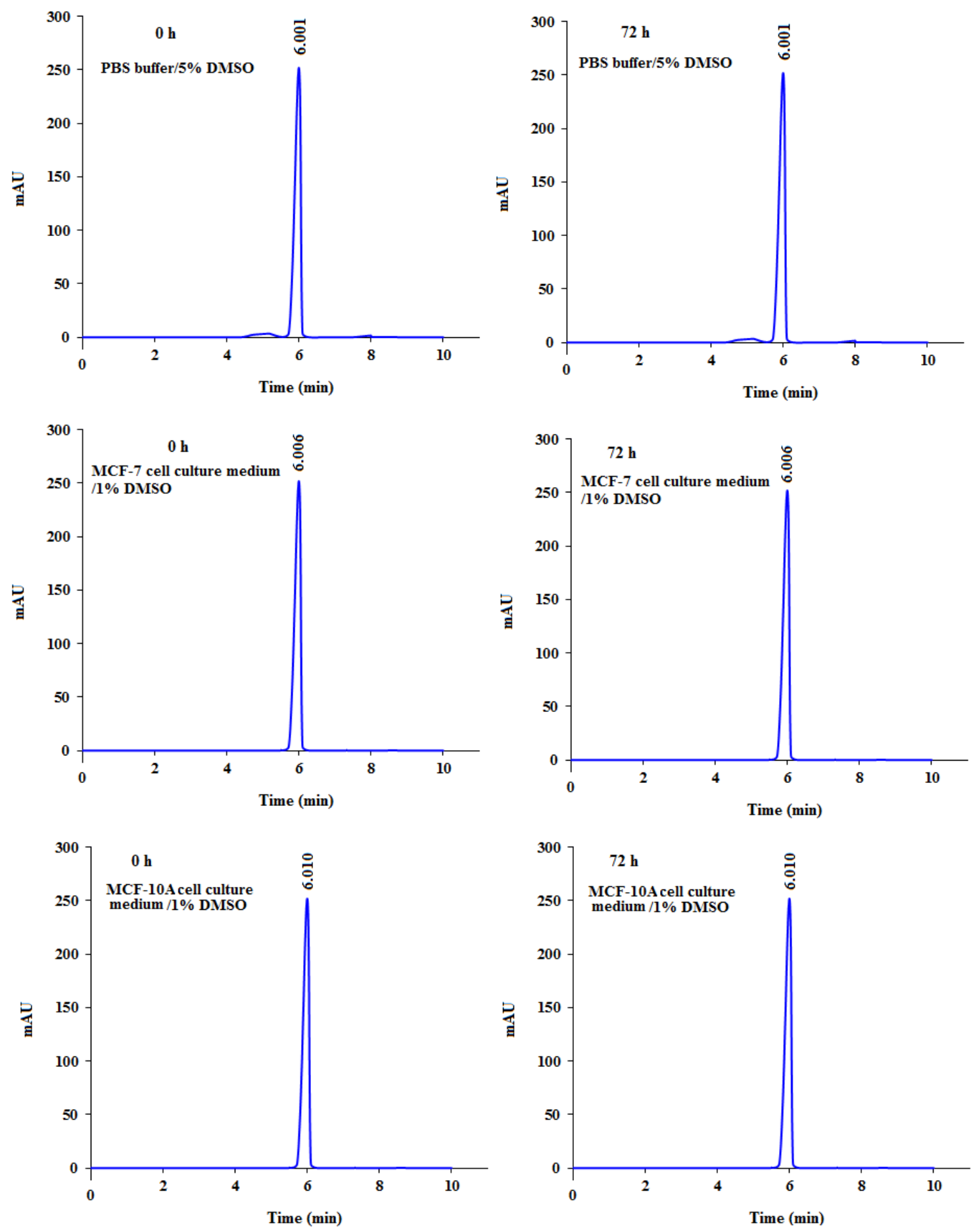

Figure S45. HPLC chromatograms of complex C-Pt1 in freshly prepared PBS buffer/5\% DMSO solution, 1\%DMSO/MCF-7 and 1\%DMSO/MCF-10A cell culture medium recorded after $0 \mathrm{~h}$ and $72 \mathrm{~h}$ incubation at $37^{\circ} \mathrm{C}$. 

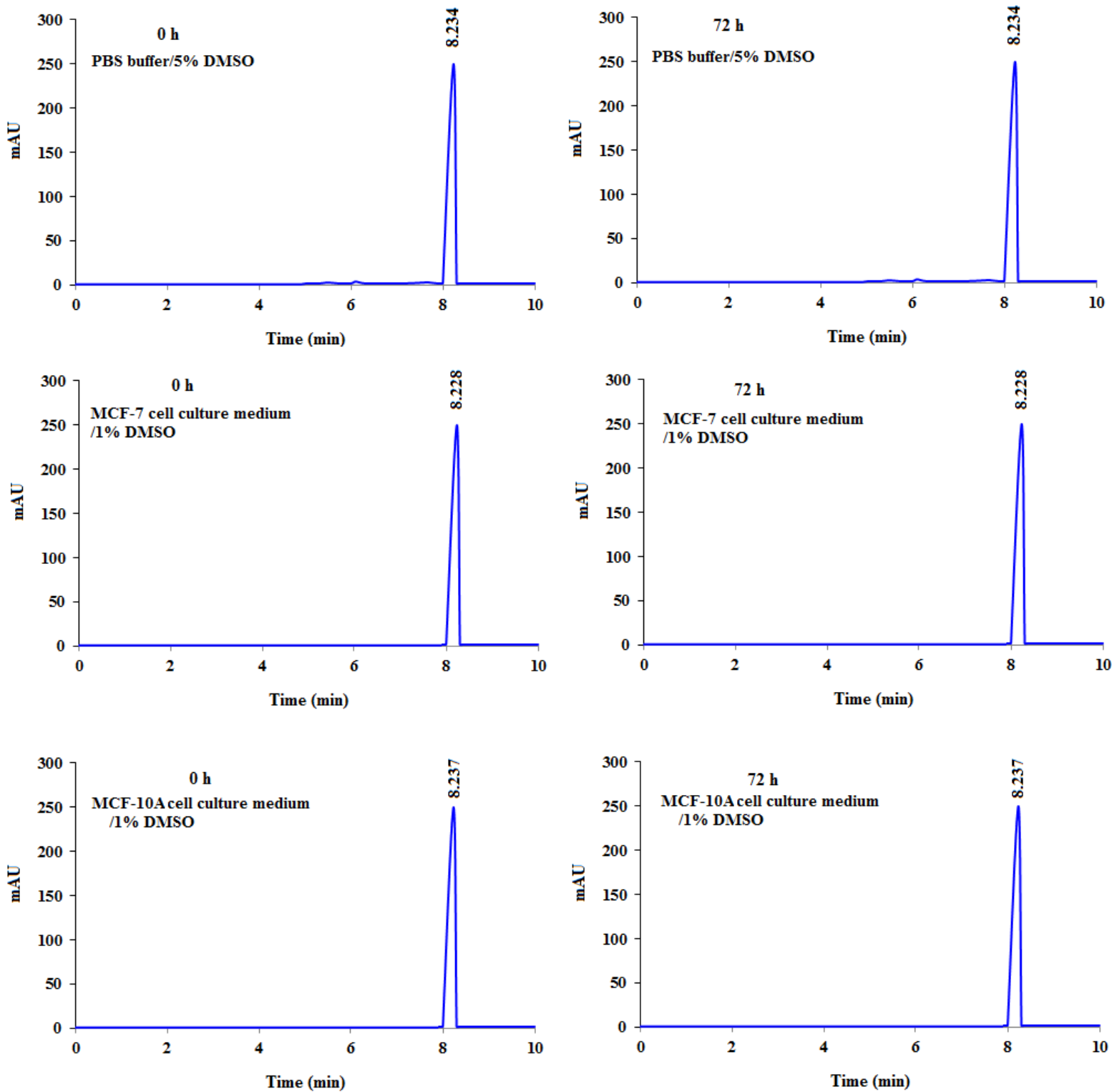

Figure S46. HPLC chromatograms of complex C-Pt2 in freshly prepared PBS buffer/5\% DMSO solution, 1\%DMSO/MCF-7 and 1\%DMSO/MCF-10A cell culture medium recorded after $0 \mathrm{~h}$ and $72 \mathrm{~h}$ incubation at $37^{\circ} \mathrm{C}$. 

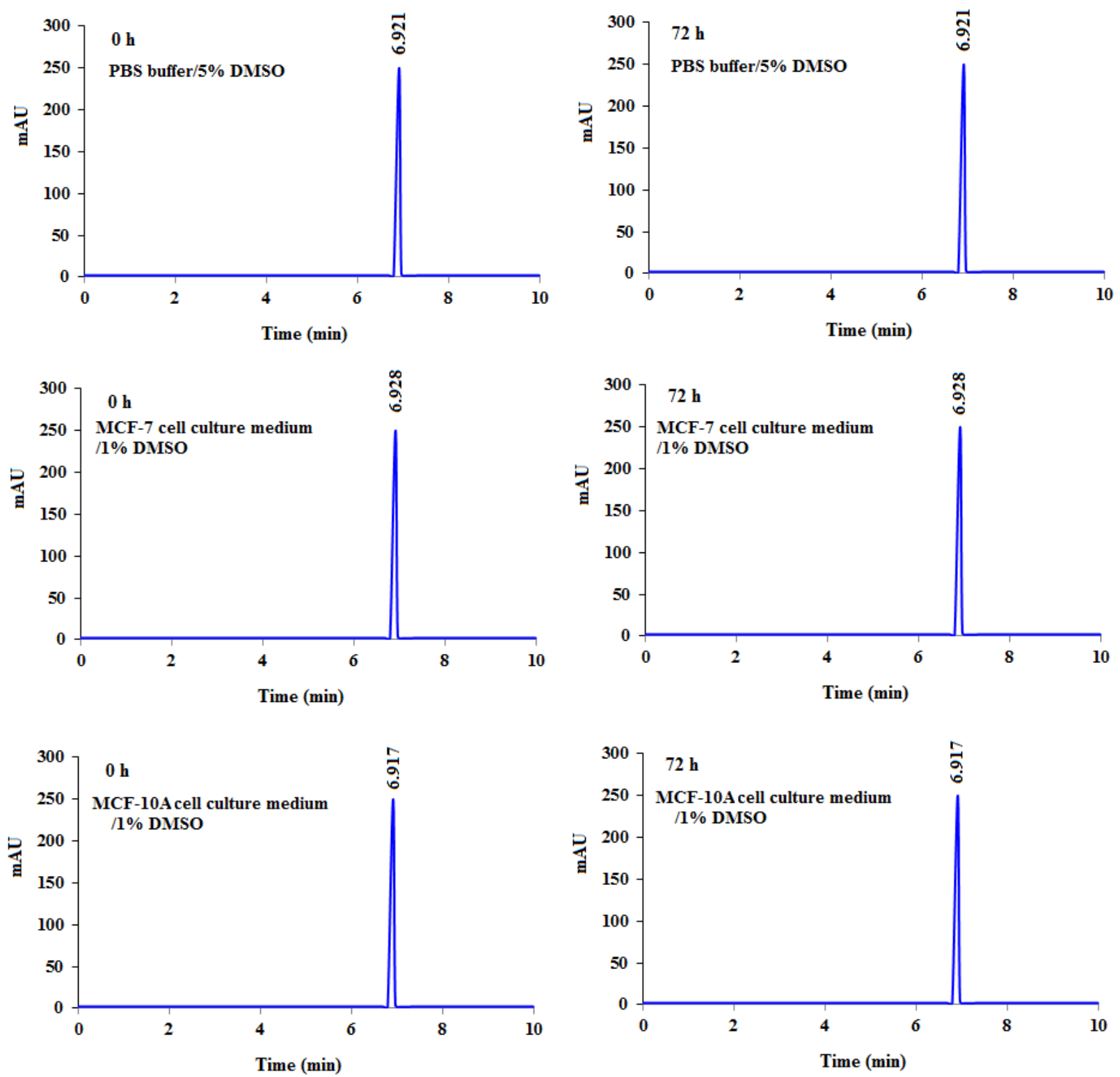

Figure S47. HPLC chromatograms of complex C-Pt3 in freshly prepared PBS buffer/5\% DMSO solution, 1\%DMSO/MCF-7 and 1\%DMSO/MCF-10A cell culture medium recorded after $0 \mathrm{~h}$ and $72 \mathrm{~h}$ incubation at $37^{\circ} \mathrm{C}$. 

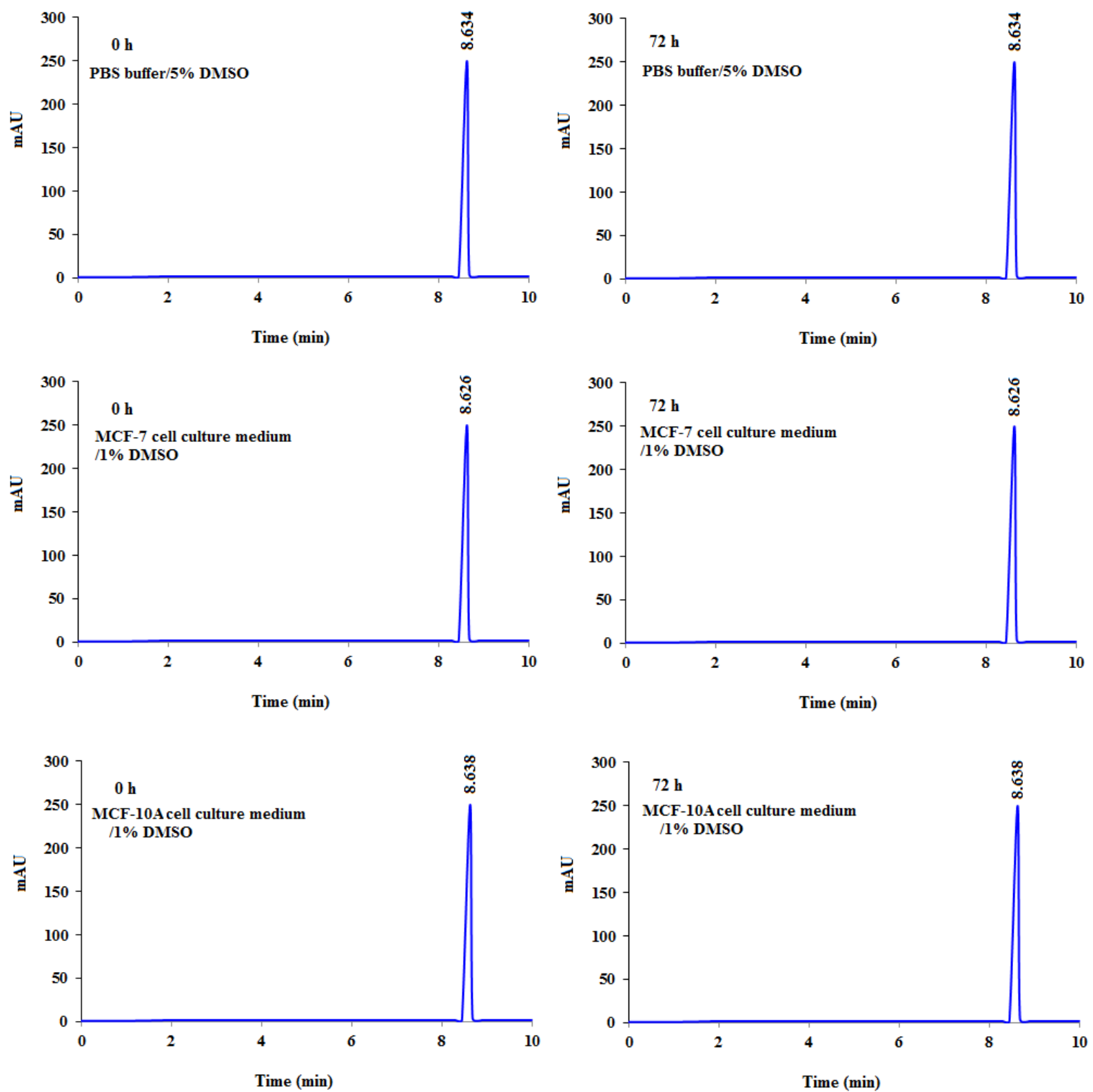

Figure S48. HPLC chromatograms of complex C-Pt4 in freshly prepared PBS buffer/5\% DMSO solution, $1 \% \mathrm{DMSO} / \mathrm{MCF}-7$ and 1\%DMSO/MCF-10A cell culture medium recorded after $0 \mathrm{~h}$ and $72 \mathrm{~h}$ incubation at $37^{\circ} \mathrm{C}$. 

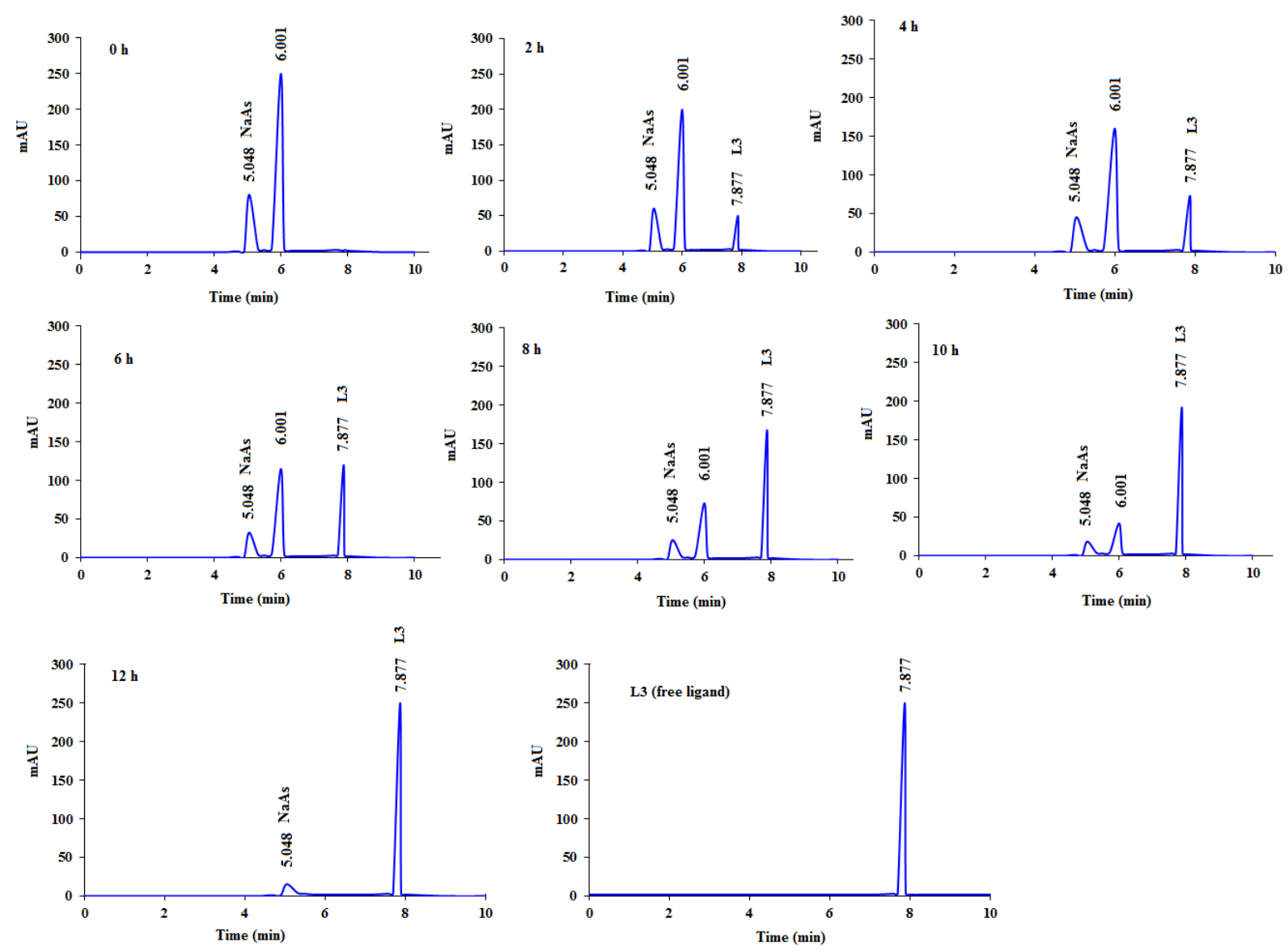

Figure S49. HPLC chromatograms of the reaction of C-Pt1 $(10 \mathrm{mM})$ with $10 \mathrm{mM}$ sodium ascorbate (NaAs) at $37{ }^{\circ} \mathrm{C}$ and $\mathrm{pH} 7$. The chromatogram of the free ligand $(\mathbf{L 3})$ is shown for comparison purposes. 

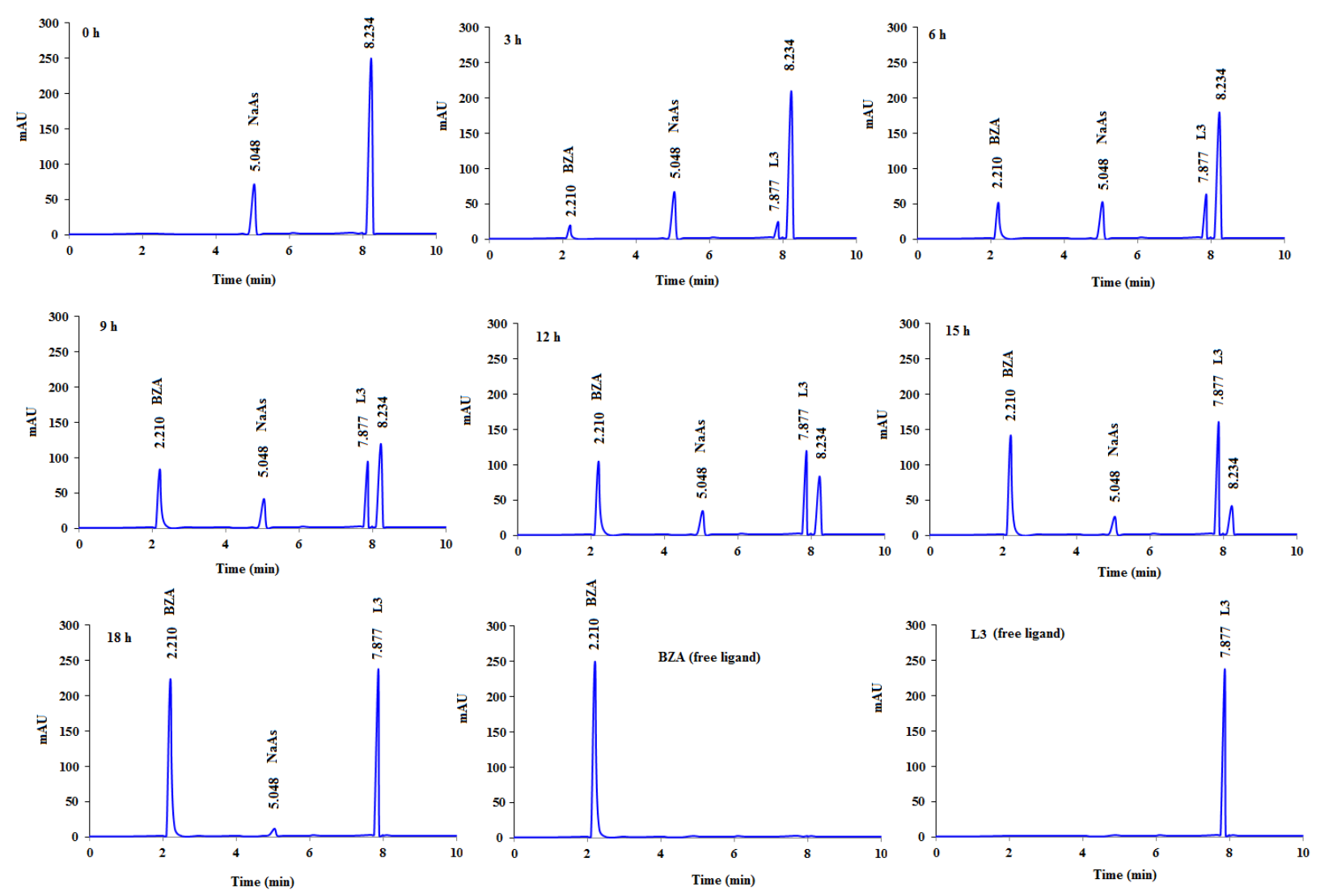

Figure S50. HPLC chromatograms of the reaction of C-Pt2 $(10 \mathrm{mM})$ with $10 \mathrm{mM}$ sodium ascorbate (NaAs) at $37{ }^{\circ} \mathrm{C}$ and $\mathrm{pH}$ 7. The chromatograms of the free ligands ( $\mathbf{L 3}$ and BZ) are shown for comparison purposes. 

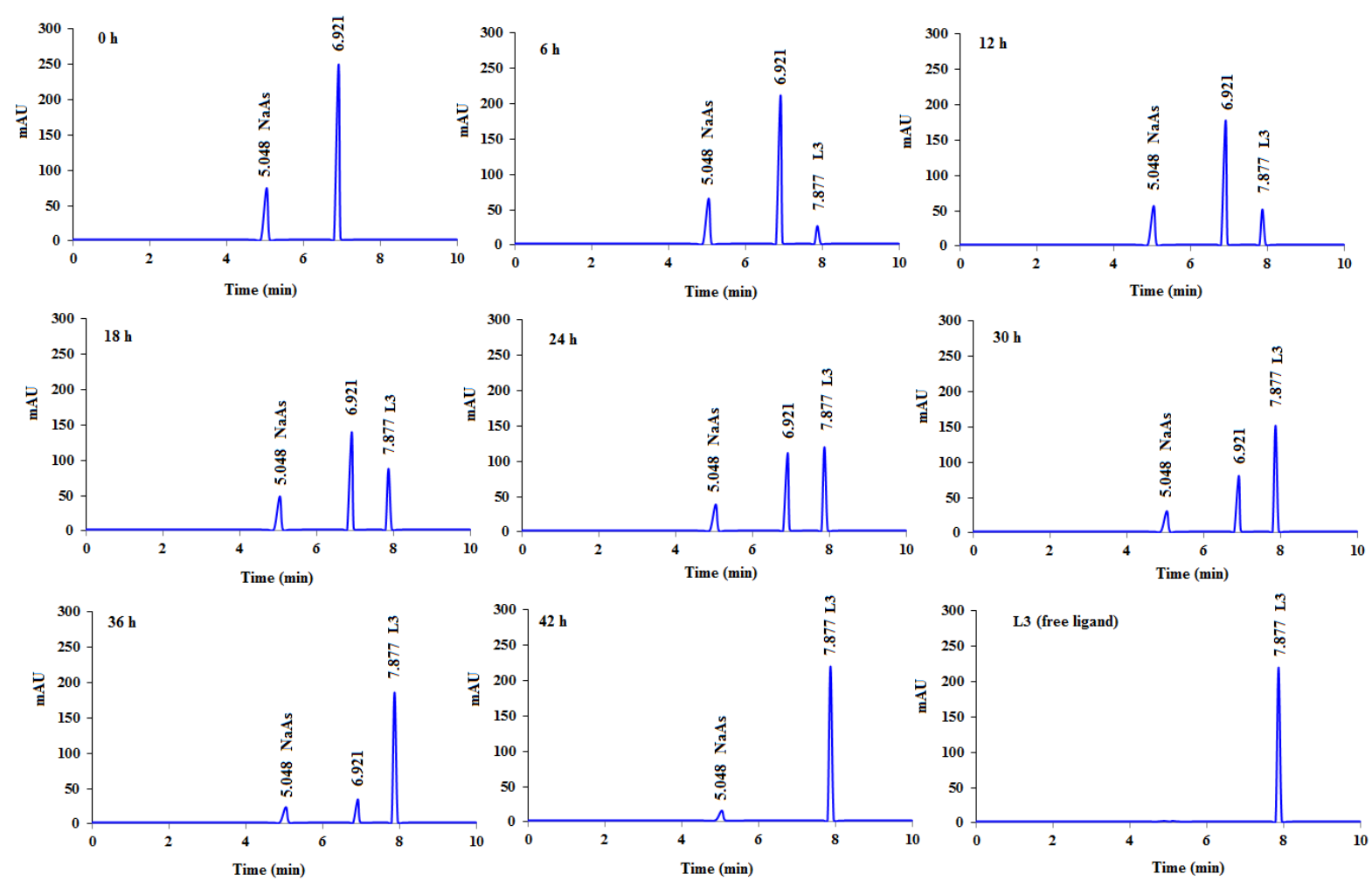

Figure S51. HPLC chromatograms of the reaction of C-Pt3 $(10 \mathrm{mM})$ with $10 \mathrm{mM}$ sodium ascorbate (NaAs) at $37{ }^{\circ} \mathrm{C}$ and $\mathrm{pH} 7$. The chromatogram of the free ligand (L3) is shown for comparison purposes. 

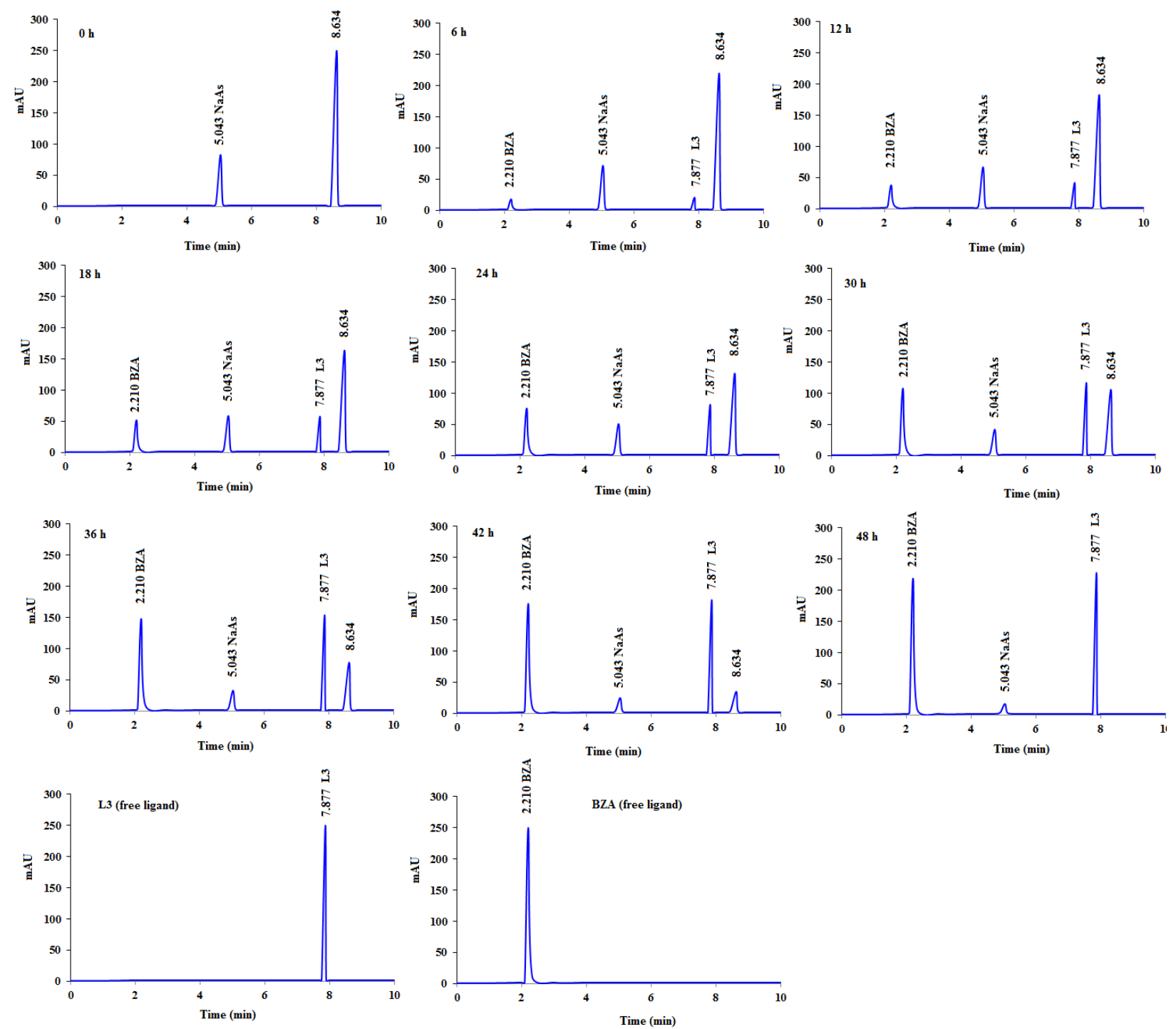

Figure S52. HPLC chromatograms of the reaction of C-Pt4 $(10 \mathrm{mM})$ with $10 \mathrm{mM}$ sodium ascorbate (NaAs) at $37{ }^{\circ} \mathrm{C}$ and $\mathrm{pH} 7$. The chromatograms of the free ligands ( $\mathbf{L 3}$ and $\mathrm{BZ}$ ) are shown for comparison purposes. 


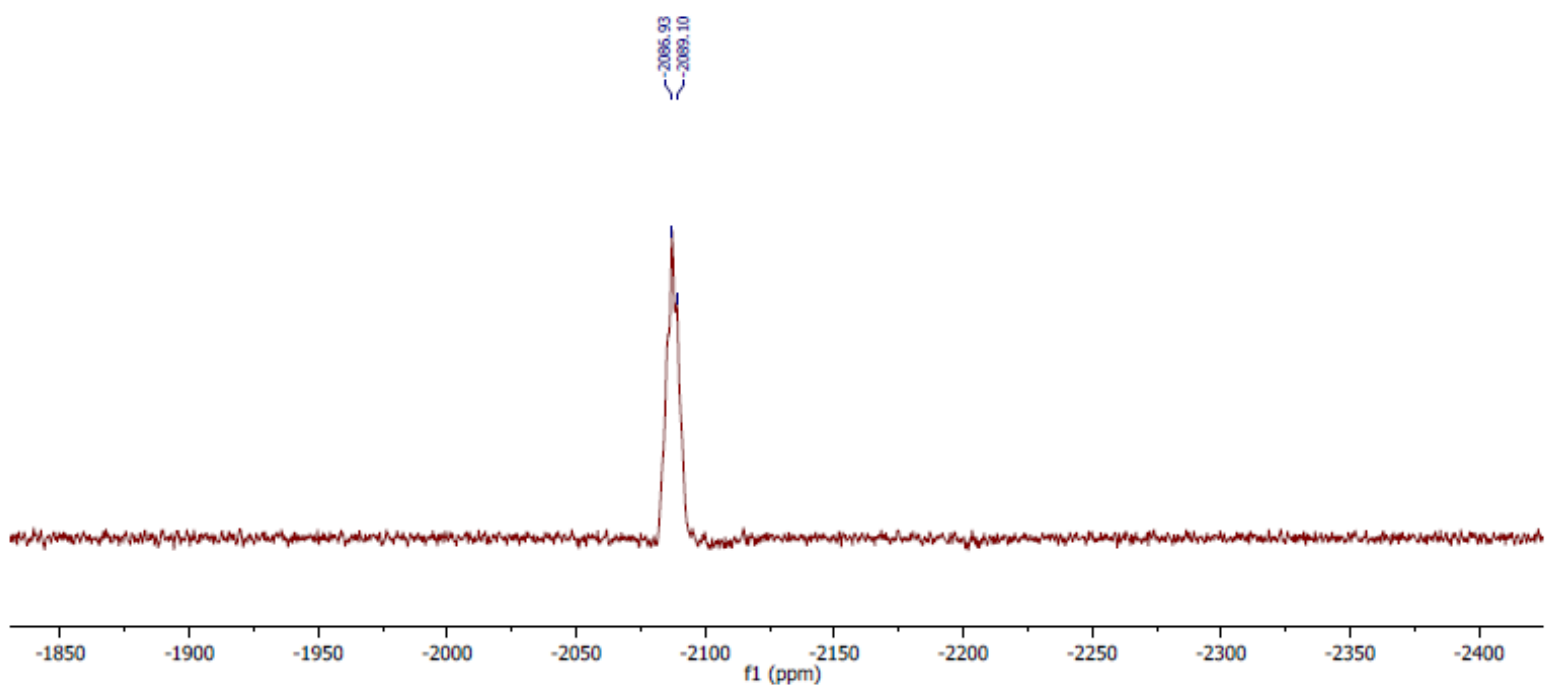

Figure S53. ${ }^{195} \mathrm{Pt}\left\{{ }^{1} \mathrm{H}\right\}$ NMR of C-Pt1 $(10 \mathrm{mM})$ in DMF $\left(\mathrm{D}_{2} \mathrm{O}\right)$ after reaction with sodium ascorbate $(10 \mathrm{mM})$ for $12 \mathrm{~h}$ at $37^{\circ} \mathrm{C}$.

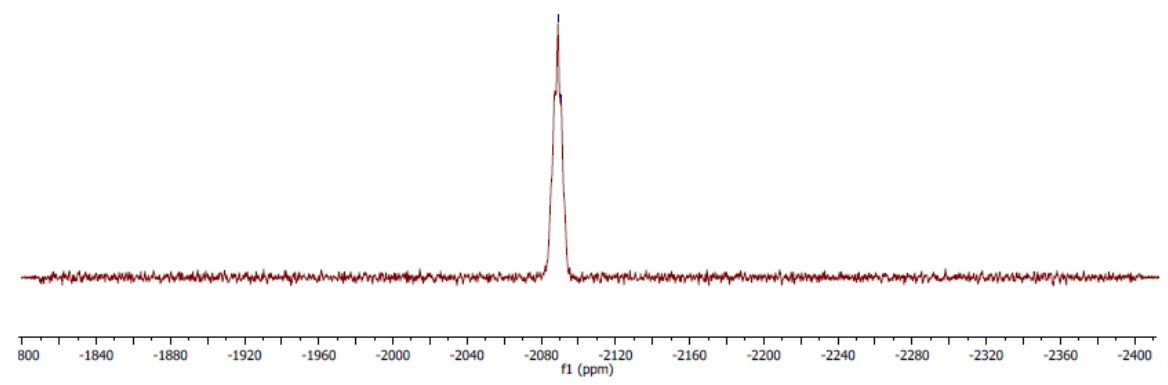

Figure S54. ${ }^{195} \mathrm{Pt}\left\{{ }^{1} \mathrm{H}\right\}$ NMR of C-Pt2 $(10 \mathrm{mM})$ in $\mathrm{DMF}\left(\mathrm{D}_{2} \mathrm{O}\right)$ after reaction with sodium ascorbate $(10 \mathrm{mM})$ for $18 \mathrm{~h}$ at $37{ }^{\circ} \mathrm{C}$. 


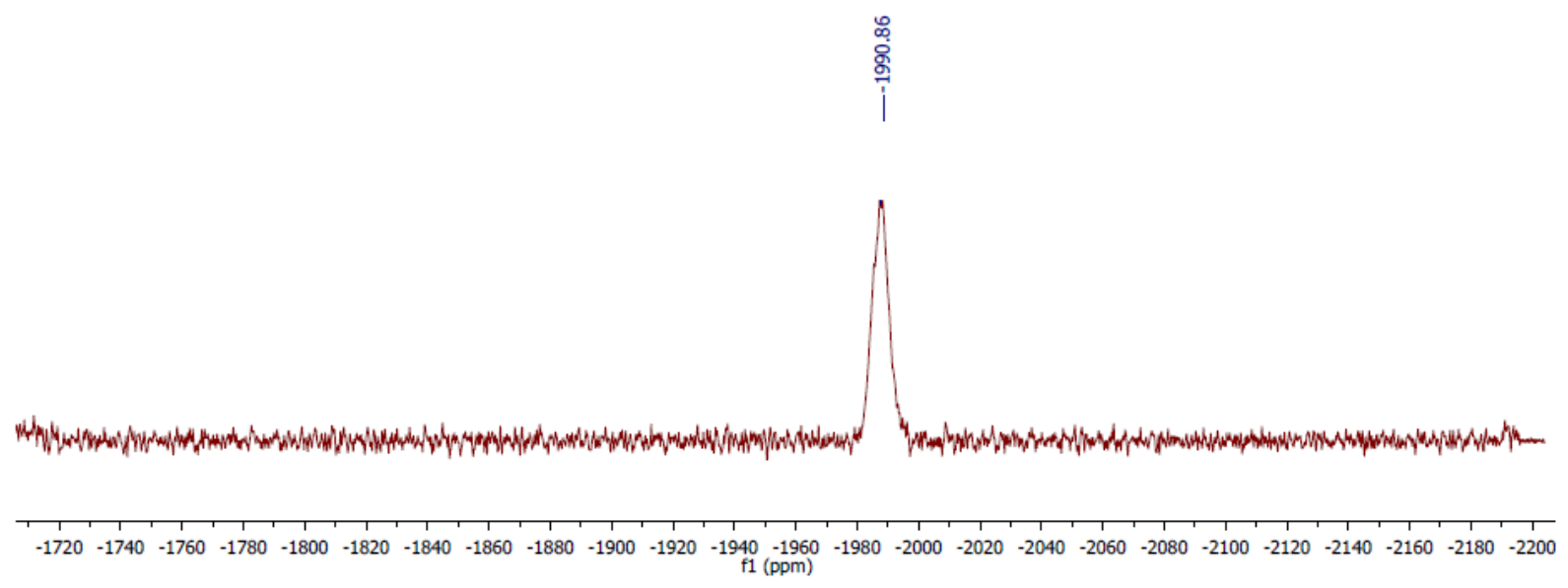

Figure S55. ${ }^{195} \mathrm{Pt}\left\{{ }^{1} \mathrm{H}\right\}$ NMR of C-Pt3 $(10 \mathrm{mM})$ in DMF $\left(\mathrm{D}_{2} \mathrm{O}\right)$ after reaction with sodium ascorbate $(10 \mathrm{mM})$ for $42 \mathrm{~h}$ at $37{ }^{\circ} \mathrm{C}$.

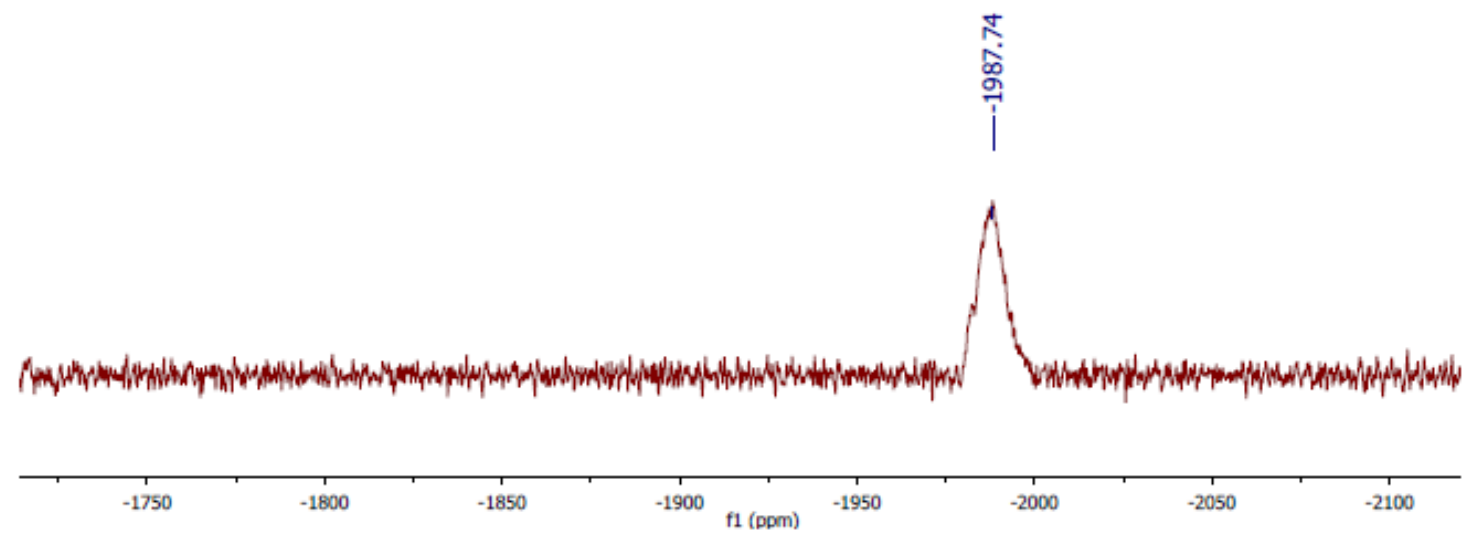

Figure S56. ${ }^{195} \mathrm{Pt}\left\{{ }^{1} \mathrm{H}\right\}$ NMR of C-Pt4 $(10 \mathrm{mM})$ in DMF $\left(\mathrm{D}_{2} \mathrm{O}\right)$ after reaction with sodium ascorbate $(10 \mathrm{mM})$ for $48 \mathrm{~h}$ at $37{ }^{\circ} \mathrm{C}$. 


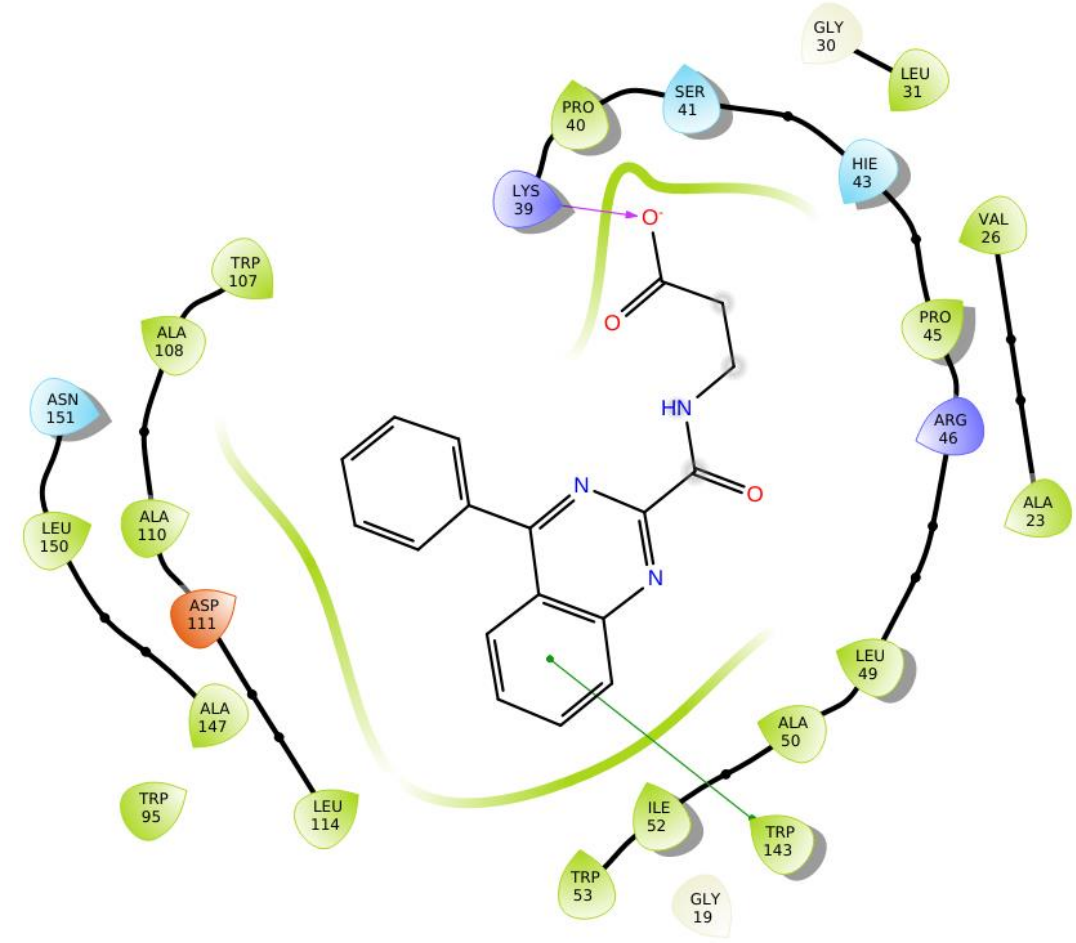

Figure S57. 2D ligand interaction diagram of $\mathbf{L 3}^{-}$computed from the docked pose. The H-bond with Lys 39 and $\pi-\pi$ interaction with Trp 143 are represented as an arrow and green line respectively. 


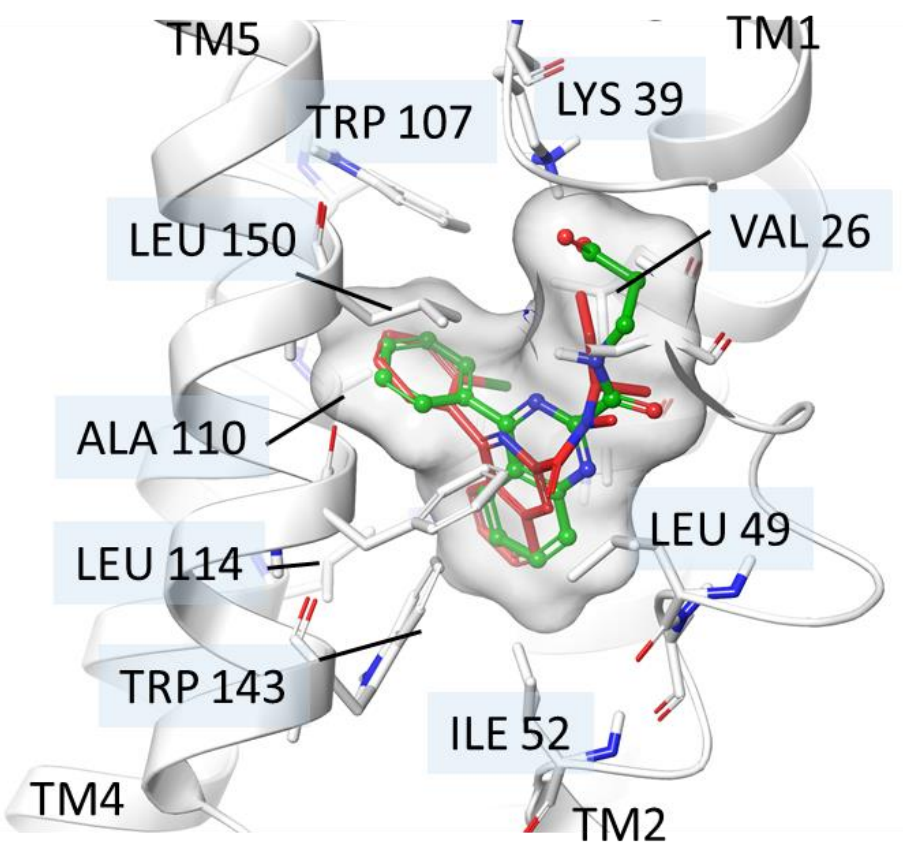

Figure S58. Superposition of docked poses of $\mathbf{L 3}^{-}$(green) on the native NMR structure of PK11195 (red) of PDB 2MGY. 

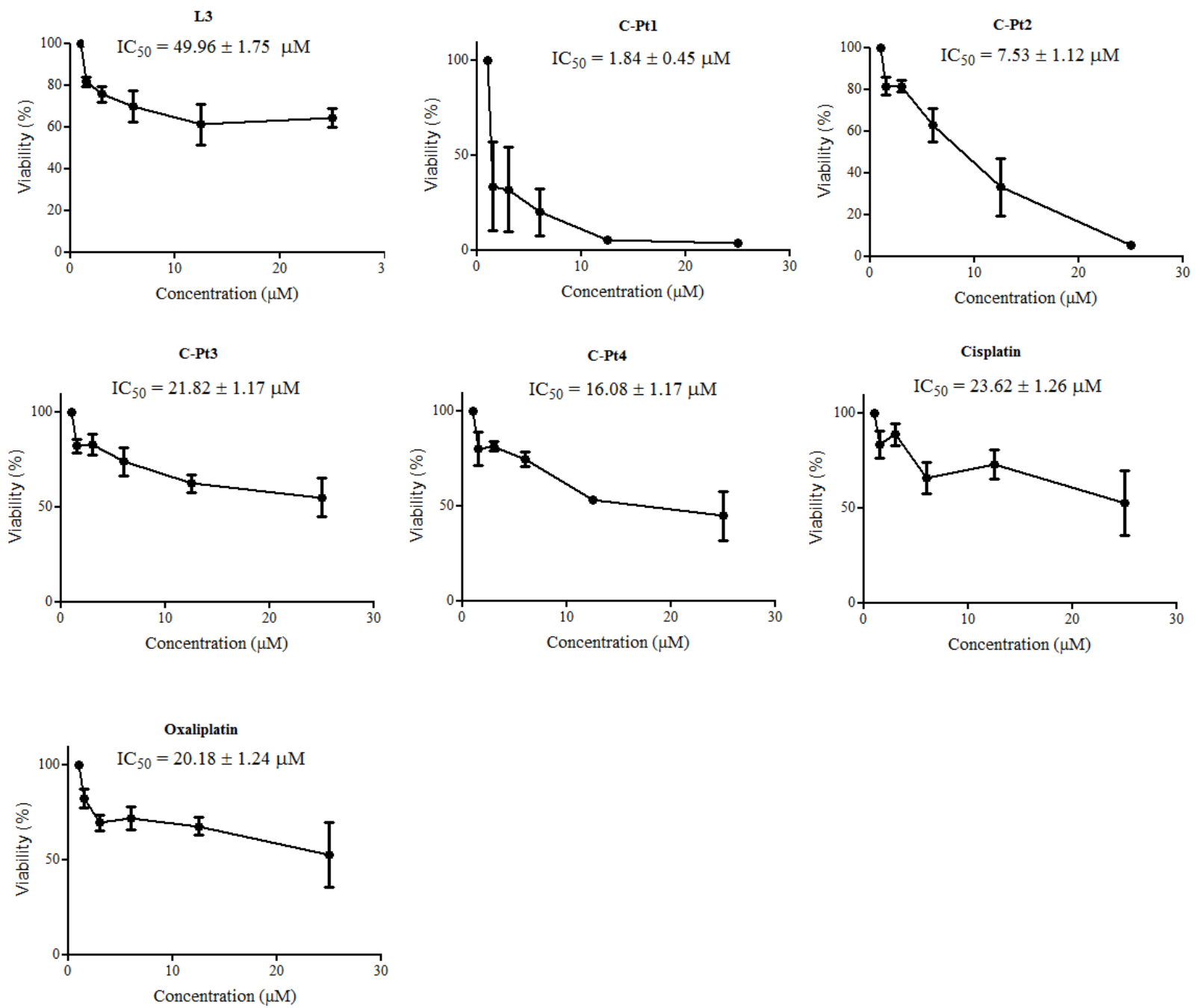

Figure S59. Graphs used for $\mathrm{IC}_{50}$ value determinations for the MCF-7 cell line. Dose-response data points represent the mean value of 3 replicates. GraphPad Prism 6 software was used to fit the data. 

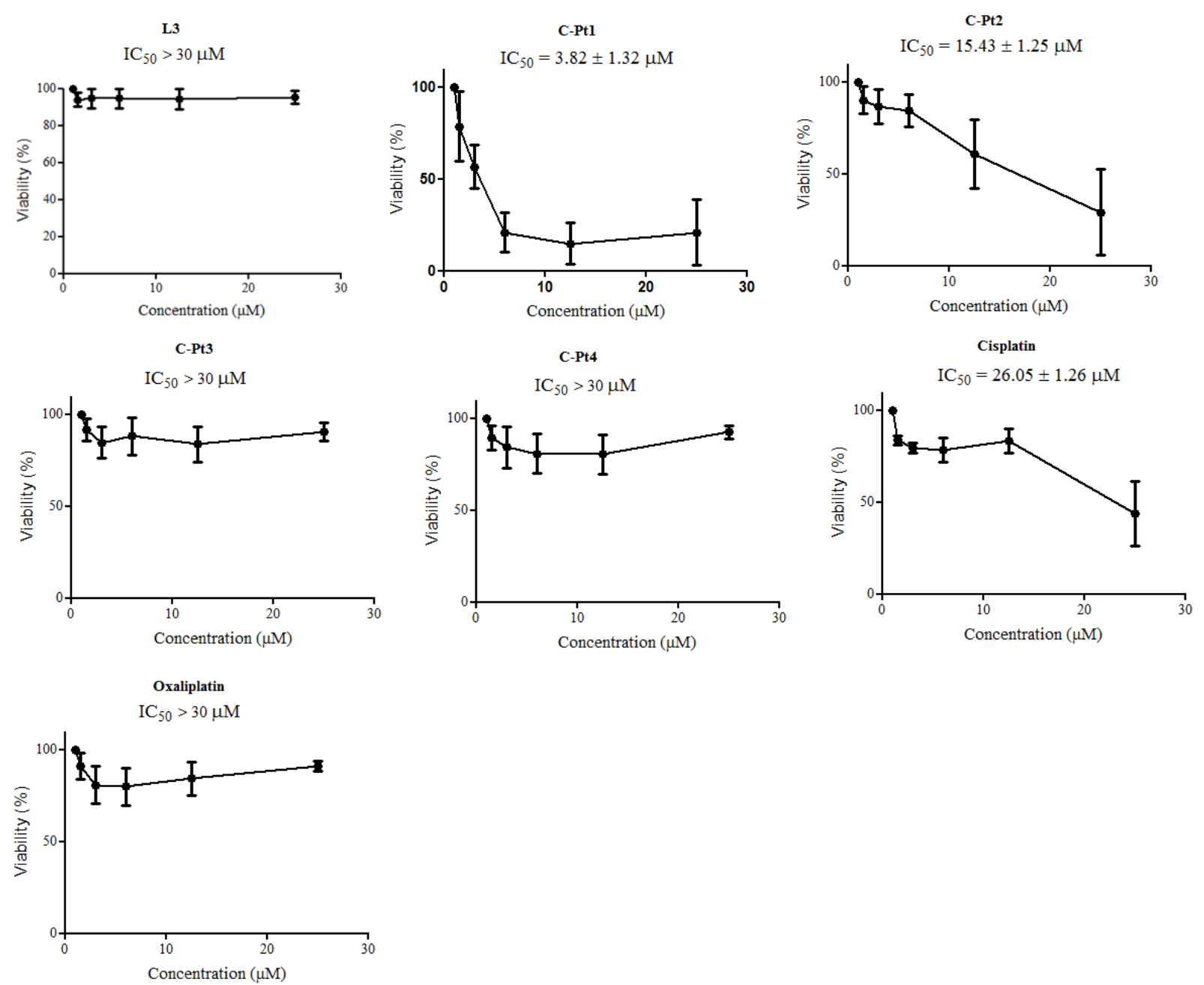

Figure S60. Graphs used for $\mathrm{IC}_{50}$ value determinations for the MCF-10A cell line. Doseresponse data points represent the mean value of 3 replicates. GraphPad Prism 6 software was used to fit the data. 